\title{
Smoking cessation in patients with respiratory diseases: a high priority, integral component of therapy
}

\author{
P. Tønnesen*, L. Carrozzi\# , K.O. Fagerström ${ }^{\curvearrowleft}$, C. Gratziou ${ }^{+}$, C. Jimenez-Ruiz ${ }^{\S}$, \\ S. Nardini ${ }^{f}$, G. Viegi**, C. Lazzaro ${ }^{\# \#, ~ I . A . ~ C a m p e l l ~}{ }^{\uparrow \uparrow}$, E. Dagli ${ }^{++}$and R. West ${ }^{\S \S}$
}

ABSTRACT: Smoking cessation is the one of the most important ways to improve the prognosis of patients with respiratory disease. The Task Force on guidelines for smoking cessation in patients with respiratory diseases was convened to provide evidence-based recommendations on smoking cessation interventions in respiratory patients.

Based on the currently available evidence and the consensus of an expert panel, the following key recommendations were made. 1) Patients with respiratory disease have a greater and more urgent need to stop smoking than the average smoker, so respiratory physicians must take a proactive and continuing role with all smokers in motivating them to stop and in providing treatment to aid smoking cessation. 2) Smoking cessation treatment should be integrated into the management of the patient's respiratory condition. 3) Therapies should include pharmacological treatment (i.e. nicotine replacement therapy, bupropion or varenicline) combined with behavioural support. 4) Respiratory physicians should receive training to ensure that they have the knowledge, attitudes and skills necessary to deliver these interventions or to refer to an appropriate specialist. 5) Although the cost of implementing these recommendations will partly be offset by a reduction in attendance for exacerbations, etc., a budget should be established to enable implementation.

Research is needed to establish optimum treatment strategies specifically for respiratory patients.

KEYWORDS: Chronic obstructive pulmonary disease, guidelines, respiratory patients, smoking cessation

\section{CONTENTS}

Introduction

Key points of the recommendations

Tobacco dependence/nicotine addiction

Tobacco smoke

Tobacco dependence

Definition of tobacco dependence

Epidemiology of smoking-related respiratory diseases

Tobacco smoking: the extent of the problem

Lung cancer

COPD

Smoking and respiratory symptoms

Smoking and lung function

Smoking and other respiratory diseases

Assessments

Smoking status

\section{AFFILIATIONS}

${ }^{*}$ Dept of Pulmonary Medicine, Gentofte Hospital, Copenhagen, Denmark.

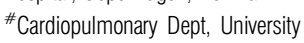
Hospital of Pisa, and **Pulmonary Environmental Epidemiology Unit, CNR Institute of Clinical Physiology, Pisa, and ${ }^{f}$ Smoking Cessation Clinic, Vittorio Veneto, and ${ }^{\# \# E c o n o m i c ~ E v a l u a t i o n ~}$ of Health Care Programmes, Pharmaco-economics and Health Economics Researching and Consulting, Milan, Italy. 'Smoker's Information Centre Helsingborg, Sweden

${ }^{+}$Smoking Cessation Clinic, Evgenidio Hospital, Medical School, Athens University, Athens, Greece.

${ }^{\S}$ Smokers Clinic, Institute of Public Health, Madrid, Spain.

"Llandough Hospital, Penarth, and

${ }^{\S \S}$ Cancer Research UK Health Behaviour Unit, Dept of Epidemiology and Public Health, University College London, London, UK.

${ }^{+}$Medical Faculty, Marmara University, Istanbul, Turkey.

CORRESPONDENCE

P. Tønnesen: Dept of Pulmonary Medicine $Y$, Gentofte University Hospital, 2900 Hellerup, Copenhagen, Denmark. Fax: 4539777693

E-mail: philipt@dadlnet.dk

Received:

May 072006

Accepted after revision:

August 282006

STATEMENT OF INTEREST

Statements of interest for R. West, K.O. Fagerström and P. Tønnesen can be found at www.erj.ersjournals.com/ misc/statements.shtml

European Respiratory Journal Print ISSN 0903-1936

Online ISSN 1399-3003 
Motivation to give up . . . . . . . . . . . . . . . . . . . . 395

Dependence . . . . . . . . . . . . . . . . . . . . . . . 396

Earlier smoking cessation experience . . . . . . . . 396

Carbon monoxide . . . . . . . . . . . . . . . . . . . . 396

Spirometry and smoking cessation . . . . . . . . . . . . 397

Comorbidity . . . . . . . . . . . . . . . . . . . . . . . . . . . 397

Characteristics of respiratory patients who smoke . . 397

Why respiratory patients are a difficult target . . . . . . 397

Self-medication for comorbidity . . . . . . . . . . . . . . 398

Dependence ... . . . . . . . . . . . . . . . . . . . . 398

Smoke inhalation pattern . . . . . . . . . . . . . . . 398

Weight control . . . . . . . . . . . . . . . . . . . . 398

Psychological and behavioural interventions . . . . . 398

Self-help programmes . . . . . . . . . . . . . . . . . . 399

Brief advice . . . . . . . . . . . . . . . . . . . . . . . . 399

Counselling . . . . . . . . . . . . . . . . . . . . . . . . 399

Behavioural therapy . . . . . . . . . . . . . . . . . . 400

Procedures for psychological and behavioural interventions in

smoking cessation . . . . . . . . . . . . . . . . . 400

Psychological and behavioural interventions in patients with

respiratory diseases who smoke ... . . . . . . . . . 400

Pharmacological treatment for smoking cessation . . . 401

First-line treatment . . . . . . . . . . . . . . . . . . 401

Second-line treatment . . . . . . . . . . . . . . . . . . 404

New medications . . . . . . . . . . . . . . . . . . . . . . . 404

Key points: pharmacotherapy and smoking cessation . . 406

\section{INTRODUCTION}

Tobacco smoking is an important contributor to respiratory diseases; it is the major aetiological factor for the development of chronic obstructive pulmonary disease (COPD) and lung cancer, and adversely affects control of asthma [1]. These diseases constitute a large part of the burden of respiratory mortality and morbidity in Europe, but tobacco smoking also negatively affects several other respiratory diseases, e.g. pneumonia and tuberculosis (TB). Smoking also contributes to the progression of some rare diseases, such as $\alpha 1$-antitrypsin deficiency and histiocytosis $X$.

Smoking cessation is the most important intervention in COPD and one of the goals of this European Respiratory Society (ERS) Task Force on guidelines for smoking cessation in patients with respiratory diseases is to ensure that pulmonary physicians act to ensure that patients with COPD and other respiratory diseases quit smoking.

Encouraging and supporting smoking cessation appears to be a low priority among pulmonary physicians, even though this intervention is highly cost-effective and is the only intervention that reduces the risk of developing COPD and slows its progression [2-4].

Smoking cessation should be an integral part of every service for pulmonary patients and every pulmonary physician should have an appropriate level of knowledge of smoking cessation. Smoking cessation should be an integral component of rehabilitation courses for COPD patients. One model study,

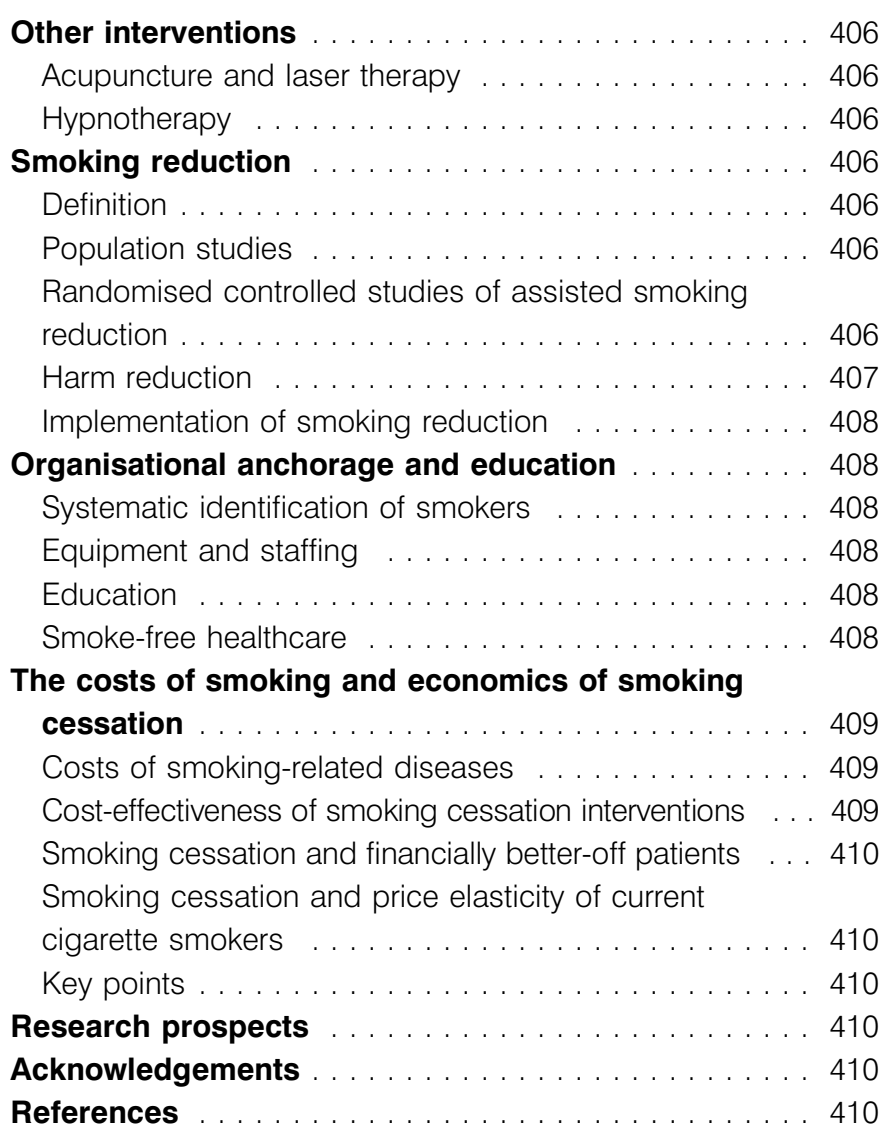

the Lung Health Study, enrolled 5,887 smokers with mild COPD and delivered repeated smoking cessation advice over a 5 -yr period [5]. The reported quit rate after 5 yrs was $\sim 35 \%$, which is an encouraging outcome. Other studies have found lower quit rates in COPD patients compared with "healthy" smokers, emphasising that there may be more obstacles to quitting in COPD patients and that more effort is needed to persuade these patients to stop smoking [6-8].

Several smoking cessation guidelines have been published in recent years. Probably the best known and most widely used guideline is the US Agency for Health Care Policy and Research's Clinical Practice Guidelines for Treating Tobacco Use and Dependence, published in 1996 [9] and updated in $2000[10,11]$. This guideline is primarily based on metaanalyses of 6,000 studies, which included many randomised clinical trials and addressed the treatment of tobacco use in healthy smokers, as well as special populations, such as pregnant females, hospitalised smokers, children, adolescents and older smokers. In accordance with the above guideline, an American College of Chest Physicians' position paper [12] was published in 2002, highlighting the key strategies and recommendations for chest clinicians.

The ERS published a position paper on smoking cessation in 1995 [13]. The American Psychiatric Association (APA) published guidelines in 1996 [14], based on a meta-analysis and intended primarily for psychiatrists; however, these guidelines might be useful to all clinicians caring for nicotinedependent patients. 
As existing guidelines for smoking cessation are more general, the present recommendations focus on patients with respiratory diseases, in order to set standards in this area and to increase the implementation of smoking cessation in this population.

Owing to a lack of scientific evidence regarding patients with respiratory diseases and smoking cessation, several of the Task Force's recommendations are not based on randomised controlled trials (RCTs) but more on expert opinions derived from clinical experience from many years of working in the field of smoking cessation with healthy smokers and patients with respiratory disorders.

The recommendations are classified according to the strength of evidence as follows. A: many well-designed RCTs. B: some evidence from randomised trials, but not optimal, for instance due to a different study population. C: no RCTs but evidence based on published data or expert opinion.

The major objectives of this ERS Task Force are: 1) to present recommendations for smoking cessation that focus on patients with respiratory diseases; 2) to increase the implementation of smoking cessation services in pulmonary departments; and 3) to stimulate research in this area.

To limit the size of the present paper, the effects from passive smoking have not been reviewed. Also omitted is smoking prevention, which plays an integral part in decreasing the adverse health effects from the pandemic of tobacco smoking.

\section{KEY POINTS OF THE RECOMMENDATIONS}

The key points of the present paper are as follows.

1. Patients with respiratory disease have a greater and more urgent need to stop smoking than the average smoker. They should be encouraged to stop but many often find it more difficult to do so (evidence level B).

2. Respiratory physicians must take a proactive and continuing role with each smoker in motivating him or her stop, provide treatment to achieve smoking cessation, however long this might take, and deal with relapses when these occur. Smoking cessation treatment must be considered integral to the management of the patient's respiratory condition. The role includes the following. (i) Regular assessment of smoking status using methods that can objectively detect smoking, such as expired-air carbon monoxide (CO) tests (evidence level C). (ii) Pharmacological treatment for nicotine dependence, including bupropion and/or, where necessary, using highdose and/or prolonged nicotine replacement therapy (NRT). It could also include giving combinations of different forms of NRT (evidence level A). Varenicline is a promising second-line agent (evidence level B). (iii) Behavioural support, which should be intensive and multi-sessional, and provided by someone who has been appropriately trained (evidence level B).

3. To carry out this role effectively, respiratory physicians must have adequate knowledge and appropriate attitudes and skills; this requires training and continuing medical education, which should be provided according to professional standards and should be accredited (evidence level C).
4. The cost of this strategy will partly be offset by a reduction in attendance for exacerbations etc., but a budget must be established to enable implementation of treatment protocols and to provide medication and behavioural support (evidence level A).

5. It is important to check lung function regularly in order to chart disease evolution, and to use this as a motivational tool (evidence level C).

6. Smokers not motivated to stop should be offered NRT to reduce smoking and as a gateway to cessation (evidence level B).

7. Smokers who are not interested in stopping or reducing should be advised that the physician will return to the question at a later visit (evidence level C).

\section{TOBACCO DEPENDENCE/NICOTINE ADDICTION Tobacco smoke}

Tobacco smoke contains $>4,000$ different constituents, including toxic substances such as carcinogens (N-nitrosoamines, aromatic hydrocarbons), ammonia, nitrogen oxide, hydrogen cyanide, $\mathrm{CO}$ and nicotine [1]. The temperature in the burning zone of a cigarette is $\sim 900^{\circ} \mathrm{C}$, with a vapour phase and a particulate phase containing particles of $\sim 0.2 \mu \mathrm{m}$ (range $0.1-$ $1.0 \mu \mathrm{m})$. The $\mathrm{CO}$ and tar content of cigarettes have been reduced during the last decade, but assessing these using "smoking machines" greatly underestimates the intake of CO and tar in smokers [15].

\section{Tobacco dependence}

Dependence on tobacco is a complex behaviour, with both environmental and genetic influences [16]. Nicotine is the main component in cigarettes that contributes to addiction, although psychological factors and habituation also play a role. Nicotine acts on specific nicotinic acetylcholine receptors in the brain, stimulating the release of dopamine that is believed to be associated with the acute rewarding effect of nicotine [17]. Chronic smoking leads to an upregulation of nicotine receptors.

\section{Definition of tobacco dependence}

In 1988, the US Surgeon General issued a report titled "Nicotine Addiction" [18]. The major conclusions were that cigarettes are addictive, that nicotine is the drug in tobacco that causes addiction and that tobacco addiction is similar to addiction to drugs such as heroin and cocaine [18]. The World Health Organization (WHO) International Classification of Diseases 10 (ICD-10) classifies tobacco smoking under "Mental and behavioural disorders" as F17, Mental and behavioural disorders due to use of tobacco [19]. Subdivisions are: F17.0, Acute intoxication; F17.1, Harmful use; F17.2, Dependence syndrome; F17.3, Withdrawal state; F17.8, Other mental and behavioural disorder; F17.9, Unspecified mental and behavioural disorder, and Z72.0, Tobacco use (which excludes F17.2 Tobacco dependence). F17.2 Tobacco dependence can be defined "as a cluster of behavioural, cognitive and physiological phenomena that develop after repeated use and typically include a strong desire to smoke, difficulty in controlling its use, persisting in its use despite harmful consequences, increased tolerance to nicotine, and a (physical) withdrawal 
state." The APA defines dependence on tobacco smoking as nicotine addiction [20].

Approximately 4-12 h after quitting smoking, varying degrees of withdrawal symptoms begin to appear. These may include irritability, anxiety, nervousness, restlessness, dysphoria (or depressed mood), difficulty concentrating, craving for cigarettes, increased appetite and sleep disturbance. Symptoms often peak within a week and then decline over several weeks to months $[21,22]$. Weight may increase by $2-3 \mathrm{~kg}$ during the first 3 months post-cessation.

The pattern of relapse after smoking cessation is comparable to that of alcohol and heroin cessation, which is highest during the first 3-6 weeks and then gradually declines [18].

Thus, tobacco smoking/nicotine addiction can be regarded as a chronic, recurrent disease or disorder with an expected successful cessation rate after treatment of $15-35 \%$ after $1 \mathrm{yr}$, similar to other addictive disorders. Several failed cessation attempts may occur before permanent abstinence is achieved. However, even if a smoker is able to stop smoking, nicotine addiction remains present for many years as shown by relapse in ex-smokers who try a single cigarette a few years after quitting.

Very simply, most smokers who smoke $>10$ (or 15) cigarettes every day and smoke their first cigarette within $1 \mathrm{~h}$ of waking are significantly addicted to tobacco, i.e. nicotine.

\section{EPIDEMIOLOGY OF SMOKING-RELATED RESPIRATORY DISEASES}

\section{Tobacco smoking: the extent of the problem}

According to the World Bank, in 1995 there were $~ 1.1$ billion smokers aged $\geqslant 15$ yrs worldwide ( $29 \%$ of the global population; $47 \%$ of males, $12 \%$ of females) [23]. This number is estimated to grow to 1.6 billion by 2025 [23]. During the period 2002-2003, the European Union (EU) average smoking prevalence was estimated at $29 \%$ (35\% of males and $22 \%$ of females; table 1) [24, 25].

Smoking is the main cause of many respiratory diseases and one of the most important risk factors for cardiovascular diseases, cancers of various organs and many other pathological conditions [26, 27].

The burden of smoking-related diseases on society is enormous. It has been estimated that $\sim 100$ million people worldwide were killed by tobacco in the 20th century, and that number will increase to 1 billion in the 21st century [28]. In particular, recent data have shown that in the year 2000, $\sim 4.83$ million deaths worldwide were attributable to tobacco smoking $(12 \%$ of the estimated total global mortality among adults aged $\geqslant 30 \mathrm{yrs}$ ), with $\sim 2.43$ million of these in industrialised countries (19\% of total adult mortality) [29]. The leading causes of death from tobacco smoking were cardiovascular diseases (1.69 million deaths), COPD (0.97 million), and lung cancer (0.85 million) [29]. Among the 50 million male smokers in the EU, 500,000 smoking-attributable deaths occur each year. At the same time, among 35 million female smokers, 105,000 smoking-attributable deaths occur annually [30]. After a 50-yr observation of male British doctors, DoLL et al. [31] concluded that smokers die $\sim 10$ yrs younger than

\begin{tabular}{|c|c|c|c|}
\hline TABLE 1 & $\begin{array}{l}\text { Smoking prevalence in the } \\
\text { during the period } 2002-20 \\
\text { otherwise stated) }\end{array}$ & $\begin{array}{l}\text { European } \\
03 \text { (except }\end{array}$ & $\begin{array}{l}\text { Jnion } \\
\text { vhere }\end{array}$ \\
\hline Country & $\begin{array}{c}\text { Total } \\
\text { smokers \% }\end{array}$ & $\begin{array}{c}\text { Male } \\
\text { smokers \% }\end{array}$ & $\begin{array}{c}\text { Female } \\
\text { smokers \% }\end{array}$ \\
\hline Austria & 29 & $32^{\#}$ & $26^{\#}$ \\
\hline Belgium & 27.5 & 33 & 22 \\
\hline Czech Republic & 30.5 & 38 & 23 \\
\hline Denmark & 27 & 30 & 24 \\
\hline Finland & 22.5 & 26 & 19 \\
\hline France & 30.5 & 36 & 25 \\
\hline Germany & 32.5 & 37 & 28 \\
\hline Greece & 45 & $51^{\circ}$ & $39^{\circ}$ \\
\hline Ireland & 27 & 28 & 26 \\
\hline Italy & $26.2^{+}$ & $30^{+}$ & $22.5^{+}$ \\
\hline The Netherlands & 30 & 33 & 27 \\
\hline Poland & 31 & 39 & 23 \\
\hline Spain & 32 & 39 & 25 \\
\hline Sweden & 17.5 & 16 & 19 \\
\hline UK & 25 & 26 & 24 \\
\hline EU average & 29 & 35 & 22 \\
\hline
\end{tabular}

nonsmokers. Cessation at ages $60,50,40$ or 30 yrs gains about $3,6,9$ or 10 yrs of life expectancy, respectively [31].

\section{Lung cancer}

Several epidemiological studies have shown that cigarette smoking is the primary factor in causing lung cancer and death from lung cancer [31].

In the EU, the incidence of lung cancer ranges 8-62 per 100,000 persons, while prevalence ranges $26-242$ per 100,000 persons [32]. In Europe, death rates from lung cancer increased by $58 \%$ between 1960 and 1988, but they declined by $14 \%$ in 1998, mainly due to the decreased incidence and mortality in males [33]. At present, lung cancer is the biggest cancer killer in the EU, accounting for $\sim 20 \%$ of all cancer deaths [33]. However, DolL et al. [31] have found that stopping smoking at age $50 \mathrm{yrs}$ halves the risk of death from lung cancer and many other diseases, while stopping by age 30 yrs almost eliminates the risk [31].

The scientific evidence showing the relationship between active smoking and lung cancer is considerable [27, 34]. The risk of developing lung cancer seems to be affected by the duration of smoking and the number of cigarettes (or cigars, or pipes) smoked daily [34]. The relative risk ratio between the occurrence of lung cancer among smokers and nonsmokers is $\sim 15$ overall and $\sim 25$ for heavy smokers [31]. However, very recently, the US Cancer Prevention Study II has shown that the number of years of tobacco smoking is far more critical in predicting lung cancer risk than the number of cigarettes smoked daily [35]. The age of smoking start is another characteristic affecting the increment in lung cancer risk [34]. The number of pack-yrs (a dimensionless index defined as number of cigarettes smoked daily $\times$ yrs of active smoking/20), 
which takes into account the duration and the amount of smoking, is probably the most accurate variable in assessing the relationship between active smoking and lung cancer. An increasing trend of lung cancer risk with an increasing number of pack-yrs has been found in many European epidemiological studies [36].

Giving up cigarette smoking reduces the risk of developing lung cancer compared with continuing to smoke, the risk becoming lower and lower as the period of abstinence from smoking increases. However, even after long periods of abstinence, the risk among former smokers remains higher than among never-smokers [27, 32].

Since the 1980s, a degree of genetic susceptibility for the disease in smokers has been recognised [34]. Recent studies seem to indicate that females are more susceptible than males to the carcinogens in tobacco smoke in the development of lung cancer [34].

\section{COPD}

According to the WHO Global Burden of Disease study, COPD, which in 1990 was the sixth leading cause of death worldwide, is expected to rank third by 2020 [37]. In the EU, mortality rates due to COPD are estimated to be two or three times higher in males than in females [38].

In the EU, prevalence rates of clinically relevant COPD differ widely between countries [38]. Surveys carried out in Europe have indicated that $\geqslant 4-6 \%$ of the adult population suffer from clinically relevant COPD, and the prevalence increases sharply with age [39].

Cigarette smoking is the most important risk factor for COPD and it can also promote the onset of exacerbations [40]. Data collected in European countries have found that self-reported diagnosis of chronic bronchitis/emphysema [41] or spirometric signs of airflow obstruction [42] are more frequent in smokers than nonsmokers.

The risk of developing COPD may be increased not only by the average daily number of cigarettes smoked but even more by cumulative pack-yrs [43]. Moreover, a Spanish study has shown that smokers with COPD have higher tobacco consumption, higher $\mathrm{CO}$ levels in exhaled air and higher dependence on nicotine than healthy smokers [44].

In recent years, many studies have suggested that females could be more susceptible to the harmful effects of tobacco smoke in developing COPD [45]. In the Copenhagen City Heart Study, the estimated excess loss of forced expiratory flow in one second (FEV1) per pack-yr was $7.4 \mathrm{~mL}$ in female smokers and $6.3 \mathrm{~mL}$ in male smokers. Female smokers also had an increased risk of hospitalisation for COPD. Similar results were noted when the end-point was deaths from COPD. This phenomenon has been explained with the more frequent and severe airway hyperresponsiveness detected in female smokers [45].

Moreover, genetic factors, such as $\alpha_{1}$-antitrypsin deficiency, may promote the development of COPD. Smoking significantly increases the risk of the disease in subjects characterised by this Mendelian genetic pattern [46].
Smoking cessation is the most effective means of preventing or decreasing the progression of COPD [47, 48]. Smoking cessation programmes seem likely to lead to a significant reduction in mortality in patients with COPD [49].

\section{Smoking and respiratory symptoms}

Data collected from general population samples have confirmed that respiratory symptoms occur more frequently among smokers than nonsmokers, in both males and females $[41,50]$. A contemporary family history for COPD showed an additive effect for the presence of bronchitis symptoms [51]. Smoking cessation significantly reduces the presence of respiratory symptoms [52].

\section{Smoking and lung function}

Both cross-sectional and longitudinal studies have demonstrated that active smoking affects lung function [53]. Smoking reduces the growth velocity of FEV1 during adolescence, causing a lower maximal attained FEV1 [54]. Smoking brings forward the time of onset of FEV1 decline in early adulthood, thus shortening the plateau phase during which lung function remains almost constant [55]. Furthermore, smoking accelerates the decline of FEV1 in late adulthood and the elderly [3, 53, 56]. This decline seems to be more rapid in females than in males once COPD is established [57]. In the Lung Health Study (LHS) the average annual loss of FEV1 was $\sim 60 \mathrm{~mL} \cdot \mathrm{yr}^{-1}$ among continuing smokers at the 11-yr follow-up point [58]. Many studies have reported a dose-response relationship between smoking and accelerated decline of FEV1 [3].

Longitudinal studies have shown that stopping smoking reduces the rate of decline of FEV1 approximately to that of the never-smoker [3,59]. FEV1 may increase somewhat after smoking cessation but it will not achieve the level expected for a never-smoker [55]. There is contrasting evidence for intermittent smokers who cease smoking and then restart (so-called "restarters"). It has been observed that restarters have a more rapid decline in FEV1 than continuous smokers and ex-smokers [60]. However, data from the LHS show that those who made several attempts to quit smoking had a reduced loss of lung function at comparable cumulative doses of cigarettes than those who continued to smoke [61]. Smoking reduction i.e. halving daily cigarette consumption for a 2-yr period, while using a nicotine inhaler, had no effect on FEV1 [62].

Active smoking also affects lung-function indices other than FEV1. An association has been observed between decrease in diffusing capacity of the lung for carbon monoxide $(D \mathrm{~L}, \mathrm{CO})$ and cumulative cigarette consumption, even in healthy subjects [63] and DL,CO can improve in subjects who quit smoking [64].

Smoking promotes a greater degree of airway hyperresponsiveness. In subjects without chronic respiratory symptoms or COPD, smoking cessation reduces airway responsiveness as measured by methacholine challenge testing. In COPD patients, smoking cessation reduces airway responsiveness to methacholine, but it does not revert to normal levels [48].

\section{Smoking and other respiratory diseases}

There are relatively few data regarding the relationship between smoking and respiratory diseases other than COPD 
or lung cancer. However, according to emerging scientific evidence, active smoking may play an important role in promoting their onset or in exacerbating their natural course. Active smoking has been associated with augmented bronchial hyperresponsiveness and total immunoglobulin (Ig)E level [64]. It is well known that asthmatic subjects have a larger decline in FEV1 than nonasthmatics; this decline appears to be larger in those who smoke $[65,66]$. Although the role of active smoking as a risk factor for asthma remains to be elucidated, symptoms are more serious and exacerbations more frequent and severe among asthmatic smokers than among asthmatic nonsmokers [64, 67]. Active smoking can alter the response to corticosteroids, thus reducing the beneficial therapeutic effects of these drugs [67]. Active smoking also increases the risks of asthma-related hospital admissions and asthma deaths [65, 68].

In asthmatics, smoking cessation, compared with unchanged smoking, improved histamine airway reactivity and respiratory symptoms after 4 months [69].

Many studies have shown that cigarette smoking is an important risk factor for community-acquired pneumonia (CAP) in adults [70]. Spanish data have allowed populationattributable risk (PAR) of tobacco smoking for the development of CAP to be estimated at $32.4 \%$ (95\% confidence interval (CI) 14.8-50.1). An augmented risk of CAP was found for increase in the duration of the smoking habit, higher average number of cigarettes smoked daily and greater cumulative cigarette consumption [71]. Additionally, mortality from CAP is correlated to cigarette consumption in a dose-response manner [68].

Current cigarette smoking is the most important risk factor for invasive pneumococcal disease among healthy adults, with a PAR of $51 \%$. A dose-response relationship has been found between this disease and the number of cigarettes smoked daily and pack-yrs [72, 73].

Active smoking has been found to promote the onset of pulmonary $\mathrm{TB}$, mainly in developing countries [73, 74], and also to increase the risk of death from TB [68].

A multi-centre case-control survey has shown that current (odds ratio (OR) 1.9, 95\% CI 1.3-2.9) and former smokers (2.3, 1.3-3.8) present a higher risk of developing idiopathic pulmonary fibrosis [75]. Epidemiological studies have not yet clarified the influence of smoking on the natural history of the disease. However, a positive smoking history, along with advanced pathological stage, male sex and increasing age, was found to be an important risk factor for long-term mortality from interstitial lung disease [76].

With regard to the onset of pneumothorax, the scientific literature has shown that the lifetime risk of developing this disease in male healthy smokers is $\sim 12 \%$. In male nonsmokers, the risk is $0.1 \%$. Such a trend is present in female "healthy" smokers but to a lesser extent [77].

\section{ASSESSMENTS}

Certain assessments of the smoker are important in order to understand what sort of help he/she needs. For that purpose it is important to understand what motivation the patient has for changing smoking behaviour, his/her degree of dependence on tobacco and any possible comorbidity that interacts with smoking cessation. The instantaneous measurement of $\mathrm{CO}$ from exhaled air is another assessment that can be very helpful to increase motivation and check progress.

\section{Smoking status}

Usually a direct question is enough. If the patient claims to be a nonsmoker but the therapist is uncertain, $\mathrm{CO}$ in exhaled air, cotinine from saliva, urine or blood and inspecting the patient's fingers and breath can yield valuable information. Smoking status should be noted prominently in the patient's record, including the type of tobacco use (cigarettes, cheroots, cigars or pipe) and quantity-inclusive pack-yrs.

\section{Motivation to give up}

A willingness or strong motivation to quit seems to be crucial for successful smoking cessation. There is no good, validated measure for assessing degree of motivation. However a straightforward way to assess the patient's willingness to give up smoking can be to ask the patient to rate, on a 10-point scale, "How important is it for you to give up smoking"? The physician can help the patient by anchoring the scale, with 10 representing "extremely important" and 0 being of "no importance".

In the clinical situation it is also useful to have an idea of perceived self-efficacy. It may therefore be informative to ask: "If you were to decide to stop smoking, how confident are you that you would succeed?", with 10 points being "entirely certain that I would succeed" and 0 "entirely certain I would fail" [78].

If readiness to give up is good, the patient should rate highly on both variables. If motivation is high but self-efficacy is low, treatment and support are critical for success. If self-efficacy is high but willingness to try is low, effective health education is critical. If a patient scores highly on both questions, a quit date can be set immediately. If both scores are low, then motivation and self-efficacy need to be built up.

Most lung physicians have too little time to spend with their patients, often only a few minutes per patient. In order to maximise the limited time available, the doctor feels a need to use that time to convey important information to the patient, often in an authoritative, one-direction manner. This style is also generally the most effective way to transfer information when time is limited. But what if the target is to change attitudes? In this case (increased willingness and motivation to change smoking behaviour), the strategy may not be ideal. Attitudes to smoking can be more difficult to change than, for instance, learning to avoid allergens. Thus a different strategy is needed, particularly since lung patients do not usually approach the physician primarily to ask for help to stop smoking. Unfortunately, a common situation is that the patient has already been advised several times by the physician or other colleagues and has failed repeatedly. These repeated failures might have affected the patient's self-esteem and selfconfidence so badly that in order to have a better balance between attitude and behaviour, they may say they are no longer willing to stop. This can just be seen as an accommodation to reality: "Why try again when I will fail anyway?"

In order to best help such smokers, the physician needs to establish a good relationship with the smoker. Normally the 
patient expects to be told to stop smoking in a direct and clear way, but this may make the patient embarrassed, and sometimes covertly, if not overtly, aggressive and defensive. Therefore, an approach where smoking can be discussed in an unthreatening, respectful and emphatic way is required.

\section{Dependence}

The vast majority of smokers smoke for the effects of nicotine and most are addicted to nicotine delivered by cigarettes. The level of dependency varies considerably. Historically, the number of cigarettes smoked daily has served as the only measure of dependence. However, research has shown that number alone is not an optimal measure of nicotine dependence [79].

Biochemical measures such as nicotine and its major metabolite, cotinine, have more recently been used as indicators of dependence. However, as nicotine has a short half-life of $\sim 2 \mathrm{~h}$, nicotine concentrations are dependent on time of day and when the last cigarette was smoked. Cotinine, with a half-life of $15-20 \mathrm{~h}$, is therefore often recommended. Both can be analysed from blood plasma, saliva and urine. For plasma cotinine, a concentration $<15 \mathrm{ng} \cdot \mathrm{mL}^{-1}$ is considered a nonsmoking level, but the majority of nonsmokers not exposed to second-hand smoke have concentrations from unmeasurable up to $10 \mathrm{ng} \cdot \mathrm{mL}^{-1}$. The smoker's average level is around $200 \mathrm{ng} \cdot \mathrm{mL}^{-1}$, but it can reach $1,000 \mathrm{ng} \cdot \mathrm{mL}^{-1}$ [80]. Several laboratories can measure plasma cotinine and it could easily be set up in most hospitals.

An indication of degree of dependence can also be obtained using questionnaires. The Fagerström Test for Nicotine Dependence (FTND) is a widely used and researched short (six-item) questionnaire [81]. The information can be obtained in an interview or the smokers can complete the questionnaire themselves (table 2). The score ranges from $0-10$ and the average in representative samples of smokers is usually 3-4 points. The two most important questions are time to first cigarette in the morning and number of cigarettes smoked daily. These two questions give almost as much information as the whole questionnaire. If time is extremely limited, time to first cigarette can be used as a proxy [79]. Another strong, but relatively infrequent, indicator of dependence is nocturnal smoking. These smokers usually score very highly on the FTND. The higher the score, the stronger is the dependence and the more difficult it is to give up. The FTND score also predicts severity of withdrawal and need for pharmacological treatment $[82,83]$ and is related to genetic determination of certain nicotinic receptors [84]. In table 2, smokers are roughly characterised according to severity of dependence.

In ICD-10 [19], seven criteria (strong desire to smoke, difficulties in controlling the amount, continued use despite harmful consequences, influencing priorities of other activities, increased tolerance, physical withdrawal) are used to diagnose tobacco dependence. Three of the seven criteria need to be fulfilled for the diagnosis. With this system, tobacco dependence can only be determined qualitatively. Some work has been done to use it as a quantitative scale [85] but no standardised data exist for such use.

\section{Earlier smoking cessation experience}

It can be valuable to ask about experiences from earlier quit attempts; for instance, about the longest period without smoking, the difficulties and withdrawal symptoms, any methods used that helped, what trigged relapse and whether anything positive was experienced during abstinence. This can give an idea of what the difficulties will be and provides an opportunity to address them better.

\section{Carbon monoxide}

Cigarette smoking leads to absorption of many toxins. $\mathrm{CO}$ is one of very few that can be easily monitored. The assessment of $\mathrm{CO}$ can be seen as an indicator of total smoke intake. The $\mathrm{CO}$ concentration can be obtained easily by asking the smoker to

TABLE 2 The Fagerström Test for Nicotine Dependence (FTND)

Question

1 How soon after you wake up do you smoke your first cigarette?

2 Do you find it difficult to refrain from smoking in places where it is forbidden?

3 Which cigarette would you hate most to give up?

4 How many cigarettes per day do you smoke?

5 Do you smoke more frequently during the first hours after waking than during the rest of the day?

6 Do you smoke if you are so ill that you are in bed most of the day?

Total score (0-10) \begin{tabular}{l} 
Response Points \\
\hline
\end{tabular}

Within $5 \mathrm{~min} \quad 3$

6-30 min 2

$31-60 \mathrm{~min}$

After $60 \mathrm{~min}$

Yes 1

No 0

The first one in the morning 1

Any other 0

$\leqslant 10 \quad 0$

$11-20$

$21-30$

$\geqslant 31$

Yes 1

No 0

Yes 1

No 0 
exhale into a $\mathrm{CO}$ analyser. The measurement unit is $\mathrm{CO}$ in ppm, which can be converted easily to carboxyhaemoglobin $(\mathrm{COHb})$. In the absence of a $\mathrm{CO}$ monitor, $\mathrm{COHb}$ can be obtained from analysis of a blood sample. Demonstrating the "CO effect" in smokers is of great motivational value. The recommended procedure is that the therapist first exhales into the device, showing the normal CO concentration of 1-3 ppm. Then the smoker blows into the machine where she/he immediately and invariably sees much higher readings of 10-20 ppm (2-5\% COHb). Under normal environmental conditions, a nonsmoker's $\mathrm{CO}$ value should not exceed 4 ppm [86].

The half-life of $\mathrm{CO}$ is $\sim 4 \mathrm{~h}$, but this is somewhat exercisedependent. Readings in the morning are therefore lower than in the afternoon [86]. Within 1-2 days after the last cigarette, the $\mathrm{CO}$ level will be normal. This rapid normalisation is very rewarding for the subject to see. After normalisation of the $\mathrm{CO}$ level, assessment can be used to monitor progress during follow-up. An abnormal CO value can be used to inform the smoker of the mechanisms by which smoking, and particularly $\mathrm{CO}$, contributes to cardiovascular disease.

If the target is reduced smoking, rather than cessation, $\mathrm{CO}$ monitoring is essential. The number of cigarettes smoked can be reduced but often the smoker compensates for the potential reduction in nicotine intake by inhaling more effectively from each of the remaining cigarettes, decreasing the possible benefit of smoking fewer cigarettes. $\mathrm{CO}$ readings, preferably taken in the afternoon, are also an indicator of dependence. As there is relatively little variation in the emission of $\mathrm{CO}$ from different cigarettes (contrary to what might be printed on the packs) the differences obtained can largely be ascribed to nicotine-seeking and dependence. COPD patients have been found to have higher $\mathrm{CO}$ readings in expired air. Whether this is the result of differences in the half-life of $\mathrm{CO}$, inflammatory production of $\mathrm{CO}$, other intrinsic factors or simply heavier smoking is not clear, but heavier smoking and different inhalation patterns appear the most likely explanations for the higher CO levels in COPD patients [87].

\section{Spirometry and smoking cessation}

Lung function tests are strongly advised during baseline assessment of smokers from the general population. The aims are to detect lung diseases in susceptible smokers [88-91] and to increase smoking cessation rates, as a consequence of a reinforced motivation to quit caused by the objective demonstration of lung function impairment [92].

Pulmonary patients probably minimise their own perceived risk of disease, and lung function tests may offer health professionals a tool to show objectively the effects of smoking, tailored to the individual patient.

The evidence that assessment of biomedical risk could have an effect on future smoking has been reviewed [93]. As only eight trials could be used, owing to insufficient data no firm conclusions could be drawn. However, using assessment of $\mathrm{CO}$, lung function testing, genetic risk of lung cancer or ultrasonography of carotid and femoral arteries, either separately or in combination, had no effect on abstinence rates. Nonetheless, spirometry is advised during baseline assessment of smokers from the general population, in order to detect lung diseases in susceptible smokers.

\section{Comorbidity}

Smoking can be seen as a way of coping with life's daily stresses and hassles. It has been observed that in heavy smokers there is an aggregation of clinical and subclinical problems such as schizophrenia, attention deficit hyperactive disorder, other drug dependence and abuse. However, the most researched and relevant psychiatric disorder in association with smoking is depression [94]. A history of depression and smoking often go together and may share genetic mechanisms [95] and if a smoker presents with a history of depression it is more difficult to give up smoking [96]. Depression and anxiety are very common among respiratory patients, particularly those with COPD [97]. In order to better understand and to treat depressed patients it is recommended that the physician asks the following two questions to assess depression. 1) During the past month, have you been bothered by feeling down, depressed or hopeless? 2) During the past month, have you often been bothered by having little interest or pleasure in doing things? Answering "yes" to either of the two questions is a strong sign of depression [98].

A single question to assess depression ("Did you feel down during most days of the past 2 weeks?") has also been used and found to be reasonably valid [99]. About $25 \%$ of relapses to smoking are caused by depression [84]. Those patients who have a previous history of depression or had depression in other attempts to give up smoking are more likely to suffer from depression in a new attempt. It is more common to suffer from negative mood than from real depression. These conditions usually appear between the fourth and seventh weeks of abstinence, but counselling and encouragement are usually enough to resolve them. The use of adequate medication and referral of the patient to a specialist can sometimes be necessary $[79,84]$.

\section{CHARACTERISTICS OF RESPIRATORY PATIENTS WHO SMOKE}

People smoke for many different reasons. Some may smoke to conform to a predominating behaviour and others are alone in their social environment with the smoking behaviour. Some may smoke for the same reason that most people drink alcohol, to experience a positive effect, while others may be trapped in their smoking so they experience withdrawal symptoms if they try to stop. In this section some of the characteristics of respiratory patients, particularly those with COPD, that can influence their smoking behaviour, will be discussed.

\section{Why respiratory patients are a difficult target}

The commonest and strongest motivation factor for giving up smoking is concern for health. As smokers grow older, motivation to give up increases or at least manifests itself in more quit attempts [100]. Smokers with respiratory complaints seem more motivated to stop smoking than those with no such complaints [8], particularly if they believe that smoking is a cause of their respiratory symptoms [101]. Some smokers succeed in quitting and thus drop out of the smoking population, but the majority fail. As symptoms worsen, they may try to quit again. Those who fail are likely to be those who have most difficulty giving up, for various reasons discussed 
later. At some stage in the development of respiratory symptoms, advice from a general practitioner (GP) is likely to have been given, perhaps repeatedly, and so the selection process goes on, with more and more recalcitrant smokers remaining in the population. It is also possible that respiratory patients at some stage develop "tolerance" to the quit advice, particularly if the same procedures or treatments are suggested repeatedly. It follows from this selection hypothesis that the more severe the lung disease, the more difficult it is to give up smoking. For example, in advanced stages of COPD quality of life is low and the smoking patient considers cigarettes one of the few things left that improve quality of life.

\section{Self-medication for comorbidity}

Another factor that can contribute to the difficulties faced by respiratory patients who smoke is the relatively high prevalence of depression or low mood [102, 103]. Depression is independently associated with smoking and failure to give up $[104,105]$. Depressed mood is also one of very few withdrawal symptoms that predicts relapse to smoking [106, 107]. There is some evidence that anxiety level, which is often a part of depression, is higher among COPD smokers [108]. It has also been suggested that these patients suffer from alexithymia, or lack of emotional expression [109]. They have been characterised, strikingly, as "living in emotional straitjackets" and it has been proposed that the more severely ill COPD patients can no longer become angry, depressed or even unhappy because any significant emotional change can lead to distressing symptoms and sometimes to physiological decompensation [110]. In this situation, smoking may be helpful as a kind of self-medication that controls anxiety and emotions: relapsing after a quit attempt may be a way to escape from depressive mood and anxiety. In an interesting study, WAGENA et al. [97] investigated the association between depression and COPD/asthma. An employment register was used to conduct a prospective, population-based cohort study, in which COPD/asthma and depressed mood were both selfrated by questionnaire. It was found that $10 \%$ of the nonsmoking COPD/asthma workers were depressed, while $29 \%$ of the smokers rated themselves as depressed. In the COPD/asthma group, depressed mood was twice as common as in the control group of smokers with other chronic disorders (heart and rheumatoid disease) and four times as common as in healthy smokers [97].

\section{Dependence}

Degree of dependence measured by the FTND [81] has fairly consistently been found to predict outcome in quit attempts, particularly when no pharmacological treatment is used [82]. With appropriate pharmacological treatment, the extra burden of high dependence can be alleviated to a certain extent.

The evidence that smokers who are respiratory, and particularly COPD, patients have higher dependence on tobacco is relatively strong and consistent. Smokers with COPD have a higher FTND score than average smokers [111, 112]. The same has been found of lung cancer patients [113, 114]. In Spain, a representative population study showed that smokers with COPD were more dependent on nicotine than healthier smokers (FTND scores 4.7 versus 3.1, respectively; $\mathrm{p}<0.001$ ). The same study found that only $10 \%$ of healthy smokers had high dependence whereas $28 \%$ of smokers with COPD were highly dependent. Also, almost $60 \%$ of healthy smokers had low dependence, against only one-third of smokers with COPD [87]. Each additional point on the FTND score has been significantly associated with an increase of $11 \%$ in the probability of developing COPD [115]. It is quite plausible that those with higher dependence, as reflected by higher cigarette consumption and/or by higher cotinine and $\mathrm{CO}$ concentrations, are more likely to end up with increased morbidity from smoking. In the Spanish study [87], smokers with COPD had higher concentrations of $\mathrm{CO}$ in exhaled air than healthy smokers (19.7 versus $15.4 \mathrm{ppm}$, respectively; $\mathrm{p}<0.0001)$. This higher dependence contributes to an increased risk of contracting a respiratory disease and also makes it more difficult to give up, further reinforcing the selective attrition of smokers to leave a "hard core" of highly dependent smokers.

\section{Smoke inhalation pattern}

Smokers with COPD tend to inhale more deeply and rapidly compared to healthy smokers $[111,116]$. Whereas smokers in general tend to inhale smoke in two steps, firstly taking the smoke into the mouth and upper airways and then inhaling it into the lungs, smokers with COPD seem to inhale the smoke more directly into the lungs. This practice may expose the lungs to smoke with a higher temperature. It is also possible that an increase in particle deposition can result from the physiological defects that are characteristic of COPD [117]. Remodelling of the small airways that results in airway obstruction and an increase in resistance is the primary component of airflow limitation. This means that emptying is incomplete during tidal breathing and the lung volume fails to decline to its natural equilibrium point. As a result, air trapping occurs. It could be hypothesised that with increasing severity of airflow obstruction, the deposition of particles from smoke further increases and accelerates the decline in expiratory airflow limitation.

\section{Weight control}

Managing body weight is an important issue for respiratory patients $[118,119]$. Low body mass index (BMI) is a problem for many end-stage COPD patients and is associated with a poorer prognosis. For this group of patients, the weight gain of $4-5 \mathrm{~kg}$ typically observed during the first year after quitting smoking might be an advantage. Theoretically, this might also be beneficial in lung cancer patients with decreased appetite. Although many females report fear of gaining weight after quitting, prevention of post-cessation weight gain does not increase success rates. For COPD patients with high BMI, the advantage of quitting smoking with regard to preservation of lung function is much more important than adverse effects from weight gain. As approximately one-third of postcessation weight gain is due to decrease in basal metabolic rate and two-thirds to an increase in caloric intake [120], dietary restrictions can be applied $2-3$ months after the quit date, thereby avoiding extra hardship during the early quitting process. Advice to increase exercise is also important in helping to prevent post-cessation weight gain.

\section{PSYCHOLOGICAL AND BEHAVIOURAL INTERVENTIONS}

This section focuses on psychological and behavioural interventions and their efficacy for smoking cessation. It concludes 
by discussing the application of these interventions for smokers with COPD.

Three interventions can be included as psychological and behavioural strategies to aid smoking cessation: self-help interventions, brief advice and counselling.

Abstinence rates or success are reported as: 1) continuous (sustained) quit rates, i.e. no smoking (not even a single cigarette) usually from the quit date (with a grace period of 1 or 2 weeks) up to the end-point after 6 months or $1 \mathrm{yr}$; and 2) point prevalence quit rates, i.e. subjects not having smoked during the last $24 \mathrm{~h}$ or 1 week as defined. Point prevalence rates are usually a little higher than sustained abstinence, but sustained abstinence rates reflect the long-term quit rate more accurately.

\section{Self-help programmes}

Self-help is defined as structured programming for smokers trying to quit, without intensive contact with the therapist. A review of the literature on the effectiveness of self-help materials for smoking cessation reveals increasing evidence that materials tailored for an individual smoker have an effect [121-124]. According to these data, tailored self-help materials can be recommended for smoking cessation (evidence level A).

\section{Brief advice}

Brief advice given by physicians or nurses can be defined as routinely providing smokers with some information to help them quit smoking and increase their motivation to make quit attempts. Reviews of the effectiveness of brief advice given by physicians or nurses $[125,126]$ suggest that brief advice from a doctor has a significant, although small, effect. Studies have shown a small but significant increase in the odds of quitting (OR 1.69, 95\% CI 1.45-1.98) [125]. This equates to an absolute difference in the cessation rate of $\sim 2.5 \%$ in smokers who received medical advice compared with those who did not. Thus, after brief advice is given to 50 patients, there will be one extra quitter after 6-12 months. A comparison of smoking cessation studies performed by the British Thoracic Society (BTS) has shown that brief advice does work in smokers with COPD [127].

Increasing the number of brief advice sessions does not significantly increase efficacy [128]. Advice to quit given by nurses improves cessation by $1 \%$ compared with control groups [126]. According to these data, it can be recommended that physicians give brief advice on smoking cessation to smokers, including respiratory patients who smoke. Nurses should do the same (evidence level A). However, when dealing with most pulmonary patients, brief advice cannot stand alone and much more intensive intervention is required. It is mostly the lighter smokers that respond to brief advice.

\section{Counselling}

There are three types of counselling (individual, group and telephone), which vary in terms of the manner of providing counselling and the time taken.

Individual counselling

Individual counselling is defined as a face-to-face encounter between a patient and a trained smoking cessation counsellor.
According to the most recent review, there is enough evidence to support individual counselling for smoking cessation: 25 patients need to receive individual counselling to gain one extra quitter [128]. There is a strong dose-response relationship between the session length of person-to-person contact and successful treatment outcomes. Intensive interventions are more effective than less intensive interventions (evidence level A). The evidence also suggests a dose-response relationship between number of sessions and treatment efficacy, i.e. treatments lasting more than eight sessions are significantly more effective than interventions lasting up to three sessions (evidence level A).

In conclusion, individual counselling is effective in helping patients stop smoking (evidence level A).

\section{Group counselling}

Group therapy offers individuals the opportunity to learn behavioural techniques for smoking cessation and to provide each other with mutual support. This kind of support allows more people to be treated by one therapist and could be more cost-effective than individual counselling.

Group therapy is better for helping people stop smoking than no intervention (OR 2.17; 95\% CI 1.37-3.45) and than self-help therapy $(2.04,1.60-2.60)$. There is insufficient evidence to evaluate whether group therapy is more effective, or costeffective, than intensive individual counselling [129]. However, several placebo-controlled trials with group therapy and NRT show relatively high 1-yr sustained quit rates $(\sim 30 \%)$ with NRT combined with group therapy [129]. There is no evidence about the efficacy of group therapy in respiratory patients.

The following conclusion can be drawn: group counselling is effective for smoking cessation (evidence level A). It is unclear whether group counselling is more or less effective than individual counselling (evidence level A).

\section{Telephone counselling}

Telephone counselling may have the potential to supplement face-to-face interventions or to substitute for face-to-face contact as an adjunct to self-help interventions. It can also be timed to maximise the level of support around a planned quit date and scheduled in response to the needs of the recipient. Telephone counselling can be proactive or reactive [130]. In the proactive approach, the counsellor initiates the calls to provide the smoker with support to make an attempt at quitting (OR $1.41,95 \%$ CI 1.27-1.57). Reactive counselling is provided via helplines or hotlines that take calls from smokers $(1.33,1.21-$ 1.47) [130].

Analyses of the latest systematic review and other trials revealed that proactive telephone counselling increased effectiveness when compared with standard self-help materials. However, telephone counselling as an adjunct to pharmacotherapy, or as an adjunct to face-to-face intervention without pharmacotherapy, does not improve on the effect of those interventions in healthy smokers [131-133].

The findings suggest that proactive telephone counselling is effective compared with other minimal interventions (evidence level A). 


\section{Behavioural therapy}

A comprehensive treatment should also address the behavioural/psychological part of tobacco dependence. Some form of behavioural therapy, sometimes also referred to as counselling, is therefore important in an optimal treatment approach.

\section{Aversive smoking}

Aversion therapy pairs the pleasurable stimulus of smoking a cigarette with some unpleasant stimulus. The most frequently examined procedure has been rapid smoking, which usually results in nausea. Although the latest systematic Cochrane review has found that rapid smoking might be effective, the single study that fulfilled current criteria for methodological adequacy yielded a nonsignificant trend [134]. The results suggest that there is insufficient evidence to support the use of aversive smoking to quit.

\section{Exercise therapy}

The arguments for using exercise in smoking cessation are supported by the evidence that shows that exercise has a moderating effect on many of the variables negatively affected by nicotine withdrawal. There is also evidence that exercise can have a positive effect on factors that may protect against smoking relapse [135-138]. However, the most recent systematic review suggests that there is insufficient evidence to support exercise for smoking cessation. [139].

\section{Procedures for psychological and behavioural interventions in smoking cessation}

A crucial part of the programme to help smokers quit is to arrange scheduled visits after quit day. There are different types of arrangements. Doctors must recognise that increasing the number of visits up to eight can boost the success rate. The following visit schedule can be recommended: weeks 1, 2, 4, 8 and 12, and 6 and 12 months after quit day. Some considerations should be taken into account in order to provide the smoker with the best help during the follow-up period.

At times, ex-smokers feel that they need to smoke again even more than during the first days after quitting. This feeling is very distracting for the smoker and can lead to relapse. Smokers should be advised that such feelings are common and should be encouraged to rethink their motivation to quit. The practice of rewarding activities during this phase can be very useful to alleviate this feeling [9].

Sometimes, abstinent smokers can suffer from withdrawal symptoms for long periods. Therapists should understand that it is crucial to explain the evolution of the different symptoms to patients. Smokers must understand the symptoms, duration, intensity and the evolution, as this knowledge helps them to maintain abstinence. Also, physicians should consider extending the use of pharmacotherapy beyond the recommended treatment period or use a combination of different types of pharmacological treatment. Alternatively, higher doses of NRT should be considered to alleviate the withdrawal syndrome. There is no evidence that these procedures increase health risks [140, 141].

In special situations (social occasions, eating and drinking, meeting friends, etc.), smokers can feel confident enough to try smoking just one cigarette. Often this "innocent cigarette" can immediately lead to taking up smoking again. Doctors must explain clearly to the patient that to begin smoking, even one puff, will increase urges to smoke, make quitting more difficult and put the patient at a high risk of relapse [9]. Smokers should know that an isolated lapse usually leads to failure.

Smokers who continue smoking daily 2-3 weeks after receiving adequate treatment for their addiction should be considered unsuccessful. The treatment approach for these patients could be as follows. 1) The doctor should congratulate the smoker for having made a serious quit attempt. He should explain to the smoker that, despite having failed, she/he has learnt skills that can be used in other attempts. The more attempts made, the higher the possibility of success. Doctors must encourage failed smokers to make another appointment in 2-3 months in order to make another serious attempt. 2) In some cases, the possibility of starting a harm-reduction approach can be considered.

\section{Psychological and behavioural interventions in patients with respiratory diseases who smoke}

Three studies have evaluated the efficacy of behavioural interventions for smoking cessation in patients with COPD [142-144]. The first, a small pilot study, evaluated whether use of the words "smoker's lung" instead of traditional terminology when talking with smokers with COPD had any influence on their smoking behaviour [142]. Although use of the term smoker's lung increased abstinence, the effect was not significant. In fact, the current authors dislike the term smoker's lung, as it is often used to blame the COPD smoker and put guilt on the patient.

Another study compared the efficacy of different behavioural reinforcement schedules [142]. There was no difference between prolonged abstinence rates when contingent reinforcement with lottery tickets for reduced breath $\mathrm{CO}$ was compared with contingent reinforcement with lottery tickets for self-report of reduced smoking. Also, no significant difference was found for prolonged abstinence when contingent reinforcement with lottery tickets for reduced breath $\mathrm{CO}$ was compared with reimbursing patients when they came for their scheduled visits. The third study showed that individual counselling responsive to the patients' needs and questions, combined with the use of a self-help smoking cessation manual, was not significantly more effective than physician advice to quit smoking [143].

Three older large chest clinic studies that tested the effect of different interventions on smoking cessation in outpatients with respiratory diseases, without reporting data on lung function, were published by the BTS in 1983 and 1990 [127, 145]. The first trial comprised 1,618 outpatients who attended a chest clinic. Four methods were evaluated: physician advice alone, advice plus a booklet, advice plus booklet plus placebo gum, and all three plus nicotine $2 \mathrm{mg}$ chewing gum with four follow-up visits. The overall 1-yr success rate was $9.7 \%$ (95\% CI $8.3-11.3 \%$ ), with no significant difference between the four treatment groups [127]. However, FAGERSTRÖM [79] has suggested that there might have been several methodological flaws in this study. The second and third BTS smoking cessation studies were multi-centre trials of 2,854 outpatients (87\% suffering from respiratory diseases) who attended 


\begin{tabular}{lcc} 
TABLE 3 & $\begin{array}{l}\text { One-year outcome of physician advice, letters } \\
\text { and visits }\end{array}$ \\
Outpatient visits & Physician advice & Intervention (letters) \\
\hline None & 5 & 9 \\
One or more & 9 & 13 \\
\hline
\end{tabular}

Data are presented as \% quit rates following secondary stratification of two studies $(n=2,854)$ to estimate the effects of intervention and outpatient visits. Data are taken from [144].

hospital or chest clinics [145]. Study A compared the effect of the physician's advice to stop smoking with the same advice plus a signed agreement to stop smoking by a target quit day, plus two visits by a health visitor and several encouraging letters from the physician to the patient. These two interventions were found to be of equal effect. Study B compared four groups: physician advice versus advice plus a signed agreement versus advice plus letters versus advice plus letters plus a signed agreement. Signed agreement did not affect outcome, while letters increased outcome from 5.1 to $8.7 \%$. A secondary stratification and pooled analysis of the two studies found that $5 \%$ would stop with advice alone and that postal encouragement would increase the success rate by more than half as much again. Also, outpatient visits seemed to increase the success rate (table 3 ).

Implementation of routine smoking cessation in a lung clinic was reported in a Danish study [146] that enrolled 197 light smokers $\left(<10\right.$ cigarettes $\cdot$ day $\left.^{-1}\right)$ and 310 smokers $(>10$ cigarettes $\cdot$ day $^{-1}$ ) who were not interested in participating in a formal smoking cessation programme. The lung clinic nurses applied minimal intervention consisting of nurse advice to quit (5-min duration), CO assessment, a booklet and an encouraging letter after 4-6 weeks. The control group was asked a few questions about smoking and had a $\mathrm{CO}$ assessment but no feedback. One-year point prevalence abstinence was $8.7 \%$ versus $3.6 \%(\mathrm{p}=0.025)$, while the sustained success rate was $3.1 \%$ versus $1.2 \%$ (not significant) [146]. In conclusion, physician and nurse advice, supported by encouraging letters, have been found to be more effective than advice alone in outpatients with respiratory disease, with a 1-yr abstinence rate of $\sim 10 \%$.

\section{PHARMACOLOGICAL TREATMENT FOR SMOKING CESSATION}

\section{First-line treatment}

Pharmacotherapy is an important cornerstone in the treatment of tobacco dependence. NRT and/or sustained-release bupropion, in conjunction with behavioural intervention, are recommended as first-line pharmacotherapy in current guidelines for smoking cessation [10, 147-150]. Except in the presence of contraindications, these drugs should be used in almost all patients attempting to quit smoking. Smokers of $\geqslant 10$ cigarettes day $^{-1}$ who are ready to stop should be encouraged to use NRT or bupropion to aid cessation. Health professionals who deliver smoking cessation interventions should give smokers accurate information and advice on these products.

\section{Nicotine replacement therapy}

Nicotine dependence is a significant element of tobacco addiction, so a standard approach to pharmacologically based smoking cessation has been the use of NRT. This treatment aims to replace the nicotine obtained from cigarettes, thus reducing withdrawal symptoms when stopping smoking. Various forms of NRT (chewing gum, transdermal patches, oral inhalers, nasal spray, sublingual tablets and lozenges) are effective and well tolerated (table 4) [140, 151-154].

A Cochrane meta-analysis found that NRT helps smokers to quit [140] (table 5). A total of 105 placebo-controlled, randomised trials of NRT found an odds ratio of 1.8 (95\% CI 1.7-1.9) in favour of NRT versus placebo. In absolute figures, this means an incremental increase in quit rate after $6-12$ months of $7 \%$ by using NRT for 3 months, and adding behavioural support to NRT increased the quit rate by a further $7-8 \%$. In the Cochrane meta-analysis, the 1-yr quit rate was $17 \%$ for NRT and $10 \%$ for the control group.

Early relapse is common in studies of NRT and is a predictor that the cessation attempt will fail. The recommended dosages of NRT vary depending on the degree of dependence. Use should normally be restricted to the licensed duration, but may continue for up to and beyond 3 months in instances of

\section{TABLE 4 Available nicotine replacement therapy formulations}

\begin{tabular}{|c|c|}
\hline Formulation & Marketed product \\
\hline \multirow[t]{3}{*}{ Nicotine transdermal patches } & 5 mg, 10 mg, 15 mg/16 h (Nicorette ${ }_{\circledR}$, Pfizer) \\
\hline & 7 mg, 14 mg, 21 mg/24 h (Nicotnell ${ }_{\mathbb{R}}$ TTS 10, TTS 20, TTS 30, Novartis) \\
\hline & 7 mg, 14 mg. 21 mg/24 h (NiQuitin ${ }_{B}$ CQ, GSK) \\
\hline Nicotine chewing gum & 2 mg, 4 mg (Nicorette ${ }_{\mathbb{R}}$, Pfizer; Nicotinell \\
\hline \multirow[t]{3}{*}{ Nicotine oral tablets } & 2 mg sublingual tablet (Nicorette ${ }_{\AA}$ Microtab $_{\AA}$, Pfizer) \\
\hline & $1 \mathrm{mg}$ lozenge (Nicotinell $\mathbb{\circledR}_{\mathbb{R}}$ Novartis) \\
\hline & $2 \mathrm{mg}$ and $4 \mathrm{mg}$ lozenge (NiQuitin ${ }_{\circledast} \mathrm{CQ}, \mathrm{GSK}$ ) \\
\hline Nicotine "oral" inhaler & $10 \mathrm{mg}$ inhalation cartridge, plus mouthpiece (Nicorette ${ }_{\mathbb{B}}$ Inhalator, Pfizer) \\
\hline Nicotine nasal spray & 0.5 mg per spray into each nostril (Nicorette ${ }_{\circledR}$ Nasal Spray, Pfizer) \\
\hline
\end{tabular}

TTS: transdermal therapeutic system; GSK: GlaxoSmithKline 
TABLE 5 Cochrane meta-analysis of effect of nicotine replacement therapy (NRT) formulations

\begin{tabular}{lcc} 
Smoking cessation therapy & NRT versus placebo & Abstinence rate \\
\cline { 2 - 3 } & & NRT \\
\hline All NRT formulations & $1.77(1.7-1.9)$ & 17 \\
Nicotine gum & $1.66(1.5-1.8)$ & 17 \\
Nicotine patch & $1.81(1.6-2.0)$ & 14 \\
Nicotine inhaler & $2.14(1.4-3.2)$ & 17 \\
Nicotine nasal spray & $2.35(1.6-3.4)$ & 24 \\
Nicotine sublingual tablet/lozenge & $2.05(1.9-3.3)$ & 17 \\
$\mathbf{4}$ mg gum versus 2 mg gum & $2.20(1.5-3.3)$ & \\
Fixed gum versus ad libitum gum & $1.29(0.90-1.9)$ & \\
Combination of two NRT versus single NRT & $1.42(1.1-1.8)$ & \\
Bupropion SR & $2.06(1.8-2.4)$ & \\
\hline
\end{tabular}

Data are presented as odds ratio (95\% confidence interval) or \%. Total number of subjects in analysis $n=39,503$. SR: sustained release. Data are taken from [140] except \#, taken from [141]

continuing nicotine dependency. NRT should be discontinued if the user restarts smoking [151, 152, 154].

There is little direct evidence that one NRT product is more effective than another, so the decision about which product to use should be guided by individual preferences. Higher success rates have been reported in highly dependent smokers using nicotine $4 \mathrm{mg}$ gum instead of $2 \mathrm{mg}$ gum. In some heavily dependent smokers, it may be beneficial to combine two NRT products. Combination NRT has been reported to improve outcome but long-term results are conflicting. No differences have been found between $16-\mathrm{h}$ and 24 -h nicotine patches and prolongation of treatment for $>3$ months did not increase quit rate, while higher doses of nicotine patches have resulted in modest increases in success rates. Tapering of patch dosage is not more effective than abruptly ceasing use.

Relative contraindications given for NRT are cardiovascular disease, hyperthyroidism, diabetes mellitus, severe renal or hepatic impairment and peptic ulcer. However, NRT has been shown to be safe in patients with coronary heart disease and it should be used in those patients for whom quitting smoking is one of the most important factors influencing prognosis. A risk-benefit assessment should be made as to using NRT in breastfeeding or pregnant females, taking into account the fact that continuing smoking will deliver more nicotine than NRT. Nicotine replacement is generally well tolerated. The most common adverse effects are localised irritation from nicotine, such as local skin irritation with the patch, or mucous menbrane irritation in the mouth and throat with oral preparations, which generally lessen or disappear due to development of local tolerance after a few days. In Europe, NRT is available on prescription, over the counter and on general sale.

\section{Efficacy of NRT in smokers with respiratory diseases}

Although smoking cessation is seen as the most important therapeutic measure in patients with COPD, few studies have examined the efficacy of different smoking cessation treatments in these patients. Studies in patients with COPD and in other respiratory disorders are summarised in table 6 [155-163].
One open randomised study investigated four different NRT regimens used in a daily routine in COPD patients in a lung clinic [146]. The 446 subjects had been referred to the clinic by their GP for routine chest radiography, lung function testing and evaluation of COPD diagnosis. Smokers ( $>10$ cigarettes. day $^{-1}$ ) were allocated to a nurse-conducted smoking cessation programme, with follow-up visits after 2 and 6 weeks and 3, 6, 9 and 12 months. The 12-month sustained success rates were $1.8 \%$ for the nicotine 5-mg patch group (who acted as "placebo" control), $8.7 \%$ for the nicotine $15-\mathrm{mg}$ patch group, $5.1 \%$ for the nicotine inhaler group and $3.5 \%$ for the combined nicotine inhaler plus nicotine 15-mg patch group [146]; the average success rate for the three active treatments was 5.6\% $(\mathrm{p}<0.01)$.

In another double-blind, randomised, placebo-controlled trial, seven pulmonary outpatient clinics enrolled 370 COPD patients who smoked a mean of 19.6 cigarettes $\cdot$ day $^{-1}$ (mean of 42.7 pack-yrs) and with a mean FEV1 of $56 \%$ predicted [161]. Subjects were treated with nicotine 2-mg sublingual tablet or placebo for 12 weeks, combined with either low support (four visits plus six telephone calls) or high support (seven visits plus five telephone calls), provided by nurses. Smoking cessation rates were statistically significantly superior with sublingual nicotine versus placebo for 6 -month (23 versus $10 \%$ ) and 12-month (17 versus $10 \%$ ) point prevalence abstinence. There was no significant difference in effect between low versus high behavioural support. The St George Respiratory Questionnaire (SGRQ) score improved significantly in abstainers versus non-abstainers; changes in mean scores after $1 \mathrm{yr}$ were -10.9 versus -2.9 for total score, and -28.6 versus 2.3 for symptom score, respectively. This trial demonstrated the longterm efficacy of NRT for cessation for the general population of COPD smokers, regardless of daily cigarette consumption, as patients smoking $<10$ cigarettes day $^{-1}$ were included. Cessation success rates were in the same range as in healthy smokers, and abstinence improved SGRQ scores [161].

The Lung Health Study [152] was a multi-centre, randomised, controlled trial designed to investigate a programme incorporating a smoking cessation intervention and regular 
TABLE 6 One-year success rates from smoking cessation studies in patients with respiratory diseases who smoke.

\begin{tabular}{|c|c|c|c|c|}
\hline \multirow[t]{2}{*}{ First author/society [Ref.] } & \multirow[t]{2}{*}{ Patients n } & \multicolumn{2}{|c|}{ Sustained success $\%$} & \multirow[t]{2}{*}{ p-value } \\
\hline & & Intervention & Control/usual care & \\
\hline \multicolumn{5}{|l|}{ Hospitalised patients } \\
\hline CAmpBell [156] & 111 & 20 (+NRT/placebo) & 20 & NS \\
\hline CAMPBeLL [157] & 234 & 21 (+NRT/placebo) & 14 & NS \\
\hline \multirow[t]{2}{*}{ LEWIS [159] } & $185^{\circ}$ & 6.5 (+Placebo) & 4.9 & NS \\
\hline & & $9.7(+\mathrm{NRT})$ & 4.9 & NS \\
\hline \multicolumn{5}{|l|}{ Ambulatory patients } \\
\hline British Thoracic Society [127] & 1550 & 9.8 (+NRT/placebo) & 8.9 & NS \\
\hline MURRAY [61] & 5887 & $28(+\mathrm{NRT})$ & 7 & $<0.001$ \\
\hline TøNNESEN [160] & 446 & $5.6\left(+\mathrm{NRT} /\right.$ placebo $\left.^{+}\right)$ & 1.8 & $<0.01$ \\
\hline
\end{tabular}

use of an inhaled bronchodilator in 5,887 smokers with mildto-moderate COPD, with a mean \pm SD FEV1 of $2.7 \pm 0.6 \mathrm{~L}(75 \%$ pred). Subjects had a mean age of 48 yrs and a smoking history of 40 pack-yrs. An initial intensive 12-session smoking cessation programme was provided, with nicotine chewing gum plus adjunctive behavioural modification, followed by a relapse prevention programme every 4 months for $5 \mathrm{yrs}$. At entry, strong physician advice to quit was given and a targetquit day was set. Nicotine gum was used aggressively. The sustained quit rate was high in the intervention group and declined as usual over the study period i.e. from $35 \%$ after $1 \mathrm{yr}$ to $22 \%$ after 5 yrs, compared with $10 \%$ and $5 \%$, respectively, in the usual care group. The cross-sectional quit rate increased slightly during the 5 yrs to $39 \%$ in the intervention group and $22 \%$ in the usual care group (fig. 1). The other important finding was that smoking cessation significantly reduced the age-related decline in FEV1 and mortality. However, as nicotine gum was not administered in a randomised way, it was not possible to test its efficacy in this study.

Overall, this long-term approach showed that aggressive, intensive and repeated smoking cessation programmes can produce high long-term quit rates in smokers with mild airway obstruction.

\section{Sustained-release bupropion}

Bupropion hydrochloride is an antidepressive drug (an aminoketone), which has been shown to be an effective aid to cessation in smokers who smoke $>10$ cigarettes $\cdot$ day $^{-1}$ and who are motivated to stop. Bupropion inhibits neuronal re-uptake of noradrenaline and dopamine, with minimal effect on the re-uptake of serotonin and no inhibitory effect on monoamine oxidase. It has been shown to reduce the activity of these dopamine-releasing neurones and thereby may deactivate the reward circuit and reduce craving. Besides inhibiting noradrenaline and dopamine re-uptake, recent in vitro data indicate that bupropion may be a noncompetitive, functional inhibitor of nicotinic acetylcholine receptors.

Sustained-release (SR) bupropion is considered a useful option for smokers attempting to stop smoking for the first time, especially those who cannot tolerate NRT, who prefer nonnicotine treatment or who have failed to quit with NRT [2-6, 16-19]. For smoking cessation the recommended dose of bupropion SR is $150 \mathrm{mg} \cdot$ day $^{-1}$ for the first week, thereafter increasing to $300 \mathrm{mg} \cdot \mathrm{day}^{-1}$ (150 mg b.i.d.). Smokers using bupropion SR are advised to continue to smoke until the target quit day, which is set usually after 1 week of treatment. A reduced maintenance dose $\left(150 \mathrm{mg} \cdot \mathrm{day}^{-1}\right)$ is recommended in elderly smokers, or those with liver or renal impairment or

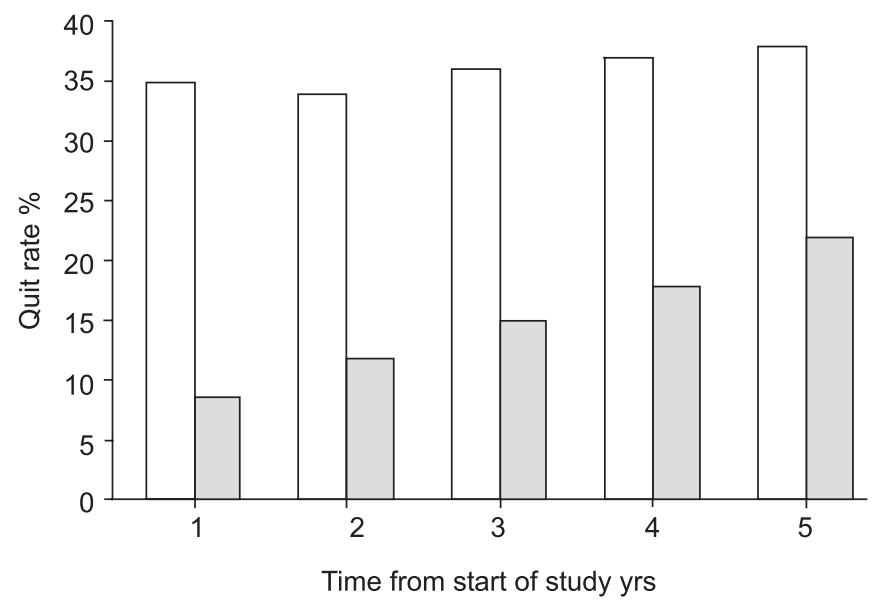

FIGURE 1. Point prevalence smoking cessation in the Lung Health Study $(n=5,587) \square$ : intervention group; $\square$ : usual care group. Reproduced from [152], with permission from the publisher. 
$<45 \mathrm{~kg}$ in bodyweight. The recommended duration of treatment for smoking cessation is 7-12 weeks. Treatment should be accompanied by a motivational support programme, highlighting additional information on quitting and relapse prevention.

Bupropion SR is a prescription-only medicine. The most common side-effects are sleep disturbances and dry mouth. A serious but rare side-effect $(<1: 1,000)$ is seizures [141]. The drug is contraindicated in patients with current or past epilepsy, and should be used with extreme caution in smokers with conditions predisposing to a low threshold for seizure, such as history of head trauma or alcohol abuse. Bupropion interacts with a number of commonly used drugs, including some antidepressants, type 1c antiarrhythmics and antipsychotics; caution is needed regarding the dose in patients with diabetes treated with hypoglycaemic agents or insulin, and in patients taking drugs that lower the seizure threshold (e.g. antipsychotics, antidepressants, theophylline and systemic corticosteroids). Bupropion is also contraindicated in patients with a history of anorexia nervosa and bulimia, severe hepatic necrosis, or bipolar disorder. Bupropion should not be used with a monoamine oxidase inhibitor, and $\geqslant 14$ days should elapse between stopping such treatment and starting bupropion [9, 140, 164-167].

\section{Efficacy of bupropion SR in patients with COPD who smoke}

The clinical efficacy of bupropion SR in the general smoking population has been established in several well-controlled trials. [8, 162, 163, 168-170]. A meta-analysis of 19 studies reported an OR of 2.06 (95\% CI 1.8-2.4) in favour of bupropion SR versus placebo [163]. Beyond randomised clinical trials, the effectiveness of bupropion SR has been shown in clinical practice and managed-care settings. A treatment period of $7-$ 12 weeks with bupropion SR seems an adequate treatment duration for smoking cessation, although longer treatment prolongs time to relapse. Recycling (i.e. repeated treatment with bupropion in smokers treated previously with bupropion) should be tried as this has been shown to increase successful outcome [171]. Treatment with bupropion SR should be accompanied by a motivational support programme highlighting additional information on quitting and relapse prevention [9-12, 147, 162].

Very few studies have used bupropion SR for smoking cessation in patients with chronic diseases such as COPD or cardiovascular diseases. A multi-centre, placebo-controlled study by TASHKIN et al. [8] examined the effectiveness of bupropion SR for 12 weeks plus weekly visits for smoking cessation among 404 patients with mild-to-moderate COPD who were smoking a mean of 28 cigarettes $\cdot$ day $^{-1}$. These subjects were relatively highly dependent, with a mean FTND score of 7 . Continuous smoking abstinence rates from weeks 4-7 were significantly higher in subjects who received bupropion SR than those who received placebo ( 28 versus $16 \%$, $\mathrm{p}=0.003)$. Continuous abstinence rates from weeks 4-12 (18 versus $10 \%$ ) and weeks $4-26$ (16 versus $9 \%$ ) were also higher in the bupropion SR group $(\mathrm{p}<0.05)$. Point prevalence quit rates at 6 months were higher in those treated with bupropion SR than in those receiving placebo (23 versus $16 \%$ ), but the 12 month continuous abstinence rates were not different statistically. Approximately one-third of a study population who were initially unwilling or unable to quit smoking were able to reduce their smoking by $\geqslant 50 \%$ during therapy with bupropion SR; $14 \%$ of these went on to achieve abstinence. These abstinence rates are much lower than those observed in similar studies with bupropion SR in healthy subjects, suggesting that COPD patients may be relatively hard core. Considering the urgent need for COPD patients to quit, a more intensive programme that results in higher quit rates seems to be required for this high-risk population.

Bupropion SR was tolerated well in these trials and seems to have a good safety profile in COPD patients. Importantly, it had no clinically significant effect on mean blood pressure in smokers, including those with hypertension, and attenuated the weight gain associated with smoking cessation, particularly in females.

Few studies have compared bupropion SR with NRT for cessation or investigated the effect of combination treatment. However, the combination of bupropion SR plus NRT seems safe and is used by many clinicians for hardcore smokers [172, 173], although comprehensive studies are missing. The choice of combinations could be based on patient preference and consideration of adverse effects and comorbidity. Market availability and cost of purchasing the medications may also influence treatment choice.

\section{Second-line treatment}

Nortriptyline, a tricyclic antidepressant, is the only other antidepressant that has demonstrated evidence of efficacy for smoking cessation. The dose of nortriptyline for smoking cessation is $75-150 \mathrm{mg} \cdot \mathrm{day}^{-1}$. A meta-analysis of four trials found an OR of 2.8 (95\% CI 1.7-4.6) for 1-yr quit rates for nortriptyline versus placebo [141]. However, there are many contraindications with nortriptyline, including common anticholinergic side-effects and particularly cardiac conduction disturbances and orthostatic blood-pressure drop.

Several other antidepressants, including selective serotonin reuptake inhibitors (i.e. doxepin, fluoxetine, sertraline, moclobemide and venlafaxine) have not been found to be effective in smoking cessation.

Clonidine, an imidazoline used in the management of hypertension, has limited efficacy as a smoking cessation therapy $[174,175]$. It has been recommended as a second-line therapy in US smoking cessation guidelines [10]. However, adverse effects associated with clonidine, such as drowsiness, fatigue and dry mouth, may limit its use [174], and the present authors consider it to be obsolete.

\section{New medications}

Varenicline has been approved in the EU, is marketed in the USA and will go on the market in late 2006 to early 2007 in most European countries. Rimonabant is on the US and European markets but is approved as a weight-loss drug rather than a smoking cessation agent.

\section{Varenicline}

Varenicline is a partial agonist of the subtype of neuronal nicotinic receptors composed of $\alpha_{4}$ and $\beta_{2}$ subunits. Recent research suggests that $\alpha_{4} \beta_{2}$ nicotinic receptors play a pivotal role in nicotine dependence and craving. Results suggest that 
varenicline initially stimulates the $\alpha_{4} \beta_{2}$ receptors that mediate the effects of the nicotinic agonist on dopamine release in the nucleus accumbens (the agonist function). If nicotine is added to varenicline treatment, no increase in dopamine response is seen (the antagonist function). As varenicline combines both agonist and antagonist functions, it can reduce nicotine dependence and can also attenuate the effects of nicotine withdrawal [176, 177]. Varenicline is well absorbed and primarily excreted unchanged $(92 \%)$ in urine. It has a halflife of $17 \mathrm{~h}$ and takes $4.3 \mathrm{~h}$ to reach maximum concentration $[176,177]$. Smokers are asked to up-titrate their dose to varenicline $1 \mathrm{mg}$ twice daily during the first 7 days of treatment, to stop smoking on day 8 , and to continue treatment for 12 weeks.

Three phase III clinical trials of varenicline have been reported. Two studies, which had identical protocols, compared varenicline with placebo and with bupropion SR (table 7). The phase III results are similar to those obtained in phase II clinical trials.

The most common side-effects reported for the varenicline, bupropion SR and placebo groups were: nausea $(28,10$ and 9\%, respectively), headache $(14,11$ and $12 \%$, respectively), and abnormal dreams (12, 6 and 4\%, respectively). Although nausea in particular was reported more commonly for varenicline, the drop-out rate due to side-effects was not higher for varenicline $(10 \%)$ compared with bupropion $(14 \%)$ and placebo $(8 \%)[176,177]$.

A third study tested duration of treatment with varenicline, 12 versus 24 weeks; a slight, but significant, effect of 24 -week treatment was obtained [177].

Varenicline employs a new and interesting mechanism for the treatment of tobacco dependence. In a maintenance study, 1,927 smokers were treated open-label with varenicline for 3 months, with a 3-month point prevalence quit rate of $64.1 \%$. Successful quitters continued with varenicline for another 3 month in a double-blind design with a quit rate from week $13-52$ of 43.6 versus $36.9 \%(p=0.02)$, suggesting that some smokers may benefit from 6 months' therapy with varenicline to maintain abstinence [178].

The phase III results suggest that varenicline may be an improvement on the current treatments for smoking cessation. Owing to the small number of studies published with varenicline and the absence of studies outside smoking cessation specialist settings, of studies conducted in general practice settings with minimal support, of studies in COPD and of post-marketing experience, the present authors consider varenicline a second-line agent in smoking cessation. It is expected that with more documentation and experience varenicline will be a first-line drug in smoking cessation.

\section{Rimonabant}

Another approach in smoking cessation pharmacotherapy is to employ non-nicotinic drugs that may influence the effects of nicotine on neural pathways within the brain that have been implicated in nicotine/tobacco dependence. It has been shown in experimental animals that blockade of the cannabinoid $\mathrm{CB}_{1}$ receptors with rimonabant diminishes feeding behaviour and decreases the self-administration of nicotine and dopamine turnover in the nucleus accumbens after nicotine stimulation [179]. In addition, rimonabant attenuates the reinstatement of nicotine-seeking behaviour, evoked by noncontingent exposure to a conditioned stimulus after extinction of nicotine selfadministration [179]. As a result, scientists have recently proposed that the stimulation of $\mathrm{CB}_{1}$ receptors by endocannabinoids within the brain plays an integral role in the development and maintenance of nicotine and tobacco dependence, and rimonabant exerts its effects in addicted individuals by inhibiting this role of the endocannabinoid system [179].

Results are available from two large, multi-centre phase III trials (Studies with Rimonabant and Tobacco Use (Stratus) US and Europe) [180, 181] with similar protocols. Rimonabant $5 \mathrm{mg}$ and $20 \mathrm{mg}$ daily were tested against placebo and active treatment was given for 10 weeks. In the US study, quit rates at 10 weeks were $28 \%$ for rimonabant $20 \mathrm{mg}, 16 \%$ for rimonabant $5 \mathrm{mg}$ and $16 \%$ for placebo [180]. The difference between the 20$\mathrm{mg}$ dose and placebo was highly significant $(\mathrm{p}<0.005)$. In the European study the 10-week abstinence rates were 25, 24 and $20 \%$, respectively (not statistically significant). At 10 weeks, abstinent subjects in the 20-mg and 5-mg and placebo groups had gained 0.7, 2 and $3 \mathrm{~kg}$ of weight, respectively.

The most frequent side-effects reported with rimonabant were nausea, diarrhoea, vomiting, urinary tract infections, anxiety and upper respiratory tract infections.

Although rimonabant has shown some short-term efficacy, its effects do not seem to be significantly better than currently

TABLE 7 Continuous quit rates from week 9-52 in two phase III trials of varenicline for smoking cessation

First author [Ref.]
Quit rate \%

\section{Placebo Varenicline $2 \mathrm{mg} \cdot \mathrm{day}^{-1} \quad$ Bupropion SR $300 \mathrm{mg} \cdot \mathrm{day}^{-1}$}

GonZaLEZ [176]

JORENBY [177]
8.4

10.3
22.1

23.0
16.4

15.0 p-value 
available cessation treatments. However, with its betterdocumented efficacy on obesity treatment [181], it might be speculated that rimonabant could be useful in overweight smokers for whom weight gain is a major barrier to quitting.

\section{Key points: pharmacotherapy and smoking cessation}

1. NRT and bupropion SR are first-line treatments for smoking cessation (evidence level A). Smokers attempting to quit should be encouraged to use these drugs to aid cessation, except in the presence of contraindications (evidence level A).

2. Different NRTs (gum, patch, inhaler, nasal spray, lozenge and sublingual tablets) are equally effective as smoking cessation treatments (evidence level A).

3. Combining the nicotine patch with a self-administered form of NRT can be more effective than a single form of NRT (evidence level B).

4. NRT should be used to aid cessation in all smokers with COPD, regardless of disease severity and number of cigarettes smoked (evidence level B).

5. Combined treatment with bupropion SR and NRT might be more effective in heavy smokers (evidence level C).

6. Both NRT and bupropion SR are effective and well tolerated in smokers with stable cardiovascular disease and in COPD patients (evidence level A).

7. Nortriptyline may be used as second-line medication to treat tobacco dependence (evidence level B).

8. There is no evidence that selective serotonin re-uptake inhibitors (SSRIs) have any effect in smoking cessation.

9. Varenicline might have an additional therapeutic effect as smoking cessation treatment and is considered a second-line agent until more documentation and experience occur (evidence level B).

10. Regular follow-up visits are important and are linked with longer-term successful outcome (evidence level B).

On the basis of these conclusions and recommendations, a treatment algorithm for smoking cessation is shown in figure 2 .

\section{OTHER INTERVENTIONS}

\section{Acupuncture and laser therapy}

A Cochrane review of 20 trials found no benefit of acupuncture compared with sham acupuncture [182]. A single study has been published about laser therapy in 320 adolescents, but it did not report any effect of laser therapy [183]. Thus, acupuncture and laser therapy cannot be recommended as aids to smoking cessation.

\section{Hypnotherapy}

The Cochrane review of nine small trials of hypnotherapy found it no more effective than other behavioural interventions [184]. Hypnotherapy is difficult to evaluate in the absence of a sham procedure to control for nonspecific effects and there is no evidence to support that hypnosis per se has any effect as an aid to smoking cessation.
There is no evidence that hypnosis, acupuncture or laser therapy have any effect in smoking cessation.

\section{SMOKING REDUCTION}

\section{Definition}

It is recommended that smokers quit cigarettes completely on the target quit day as most smokers who reduce to a few cigarettes per day have a high probability of relapse. This has been documented in several smoking cessation trials, for example the Collaborative European Anti-Smoking Evaluation (CEASE) trial [165]. Complete abstinence during the first week after quitting was a very strong predictor of sustained abstinence at $1 \mathrm{yr} ; 25 \%$ for smokers who quit completely, compared with $4 \%$ for those who smoked in the first week [165].

However, many smokers would prefer to reduce the number of cigarettes smoked daily rather than quitting completely. The aim of smoking reduction is to widen access to cessation by engaging smokers who are currently unable or unwilling to stop abruptly, but who want to reduce smoking. As shown below, the concept of smoking reduction makes it possible to recruit a new group of smokers, who are not interested in abrupt cessation. The reduction process should be viewed as a gateway to complete cessation.

The definition of smoking reduction is a decrease in the number of cigarettes (or amount of tobacco) smoked daily. A $50 \%$ reduction or more in daily cigarettes has been chosen arbitrarily in most studies, confirmed by any decrease in exhaled CO levels [185, 186].

\section{Population studies}

In one US multi-city public health intervention study (Community Intervention Trial for Smoking Cessation; COMMIT) that focused on assisted cessation, $40 \%$ of smokers reduced their smoking and maintained their reduction for 3 yrs [187]. A much lower reduction rate at 5 yrs was reported in a Danish observational population study (the Copenhagen Population Study), which included 3,791 smokers; no interventions or help to quit or reduce were offered [188]. In males, a reduction in smoking of $13 \%$ was found after $5 \mathrm{yrs}$, with a decrease from a mean \pm SD of $31 \pm 12$ to $16 \pm 9$ cigarettes $\cdot$ day $^{-1}$. The male cessation rate was $9 \%$, while $78 \%$ were stable with regard to smoking behaviour. In females, the reduction rate was $9 \%$, from $27 \pm 11$ to $13 \pm 7$ cigarettes $\cdot$ day $^{-1}$. The female cessation rate was $7 \%$, and $84 \%$ did not change their smoking behaviour.

\section{Randomised controlled studies of assisted smoking reduction}

Several RCTs of smoking reduction have been published. In six studies (two using nicotine inhaler and four using nicotine chewing gum for 6 months to $1 \mathrm{yr}$ ) that enrolled a total of 2,424 smokers who were unwilling or unable to stop abruptly, a reduction in daily cigarette smoking $(>50 \%)$ was reported in $15.9 \%$ of smokers using NRT compared with $6.7 \%$ using placebo [189]. After $1 \mathrm{yr}$, smoking cessation rates were $8.4 \%$ among NRT users versus $4.1 \%$ in placebo users. A reduction in daily cigarette smoking of $>50 \%$ after 3-4 months had a strong predictive value for quitting at 1 yr. Participation in reduction trials increased motivation to quit. 


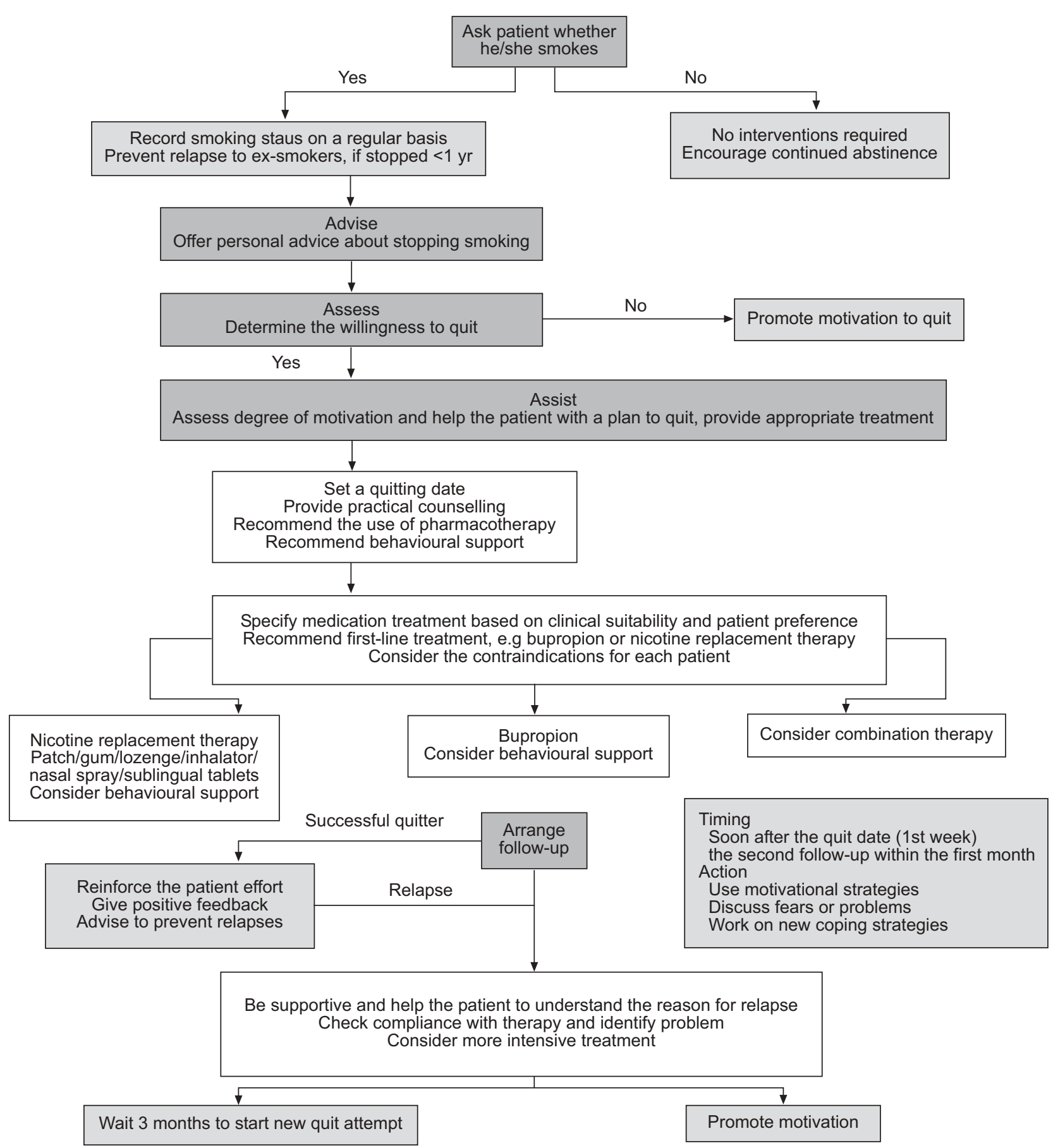

FIGURE 2. An illustration of the recommended smoking cessation steps and approved first-line interventions.

Although the number of cigarettes $\cdot$ day $^{-1}$ after 18 months decreased to $36 \%$ of baseline in the active nicotine group, the CO level only declined to $71 \%$ of baseline, suggesting a moderate degree of compensation by more effective smoking of each cigarette (deeper, longer and more inhalations per cigarette) [189].

An analysis of 19 trials of NRT for smoking reduction found reductions in cigarettes day $^{-1}$ ranging from 25\% (absolute reduction of eight cigarettes $\cdot$ day $\left.^{-1}\right)$ to $55 \%\left(23{\left.\text { cigarettes } \cdot \text { day }^{-1}\right)}^{-1}\right.$ in the NRT group compared with reductions of $13 \%$ (three cigarettes $\cdot$ day $^{-1}$ ) to $26 \%$ (eight cigarettes $\cdot$ day $^{-1}$ ) in the placebo groups [190, 191].

\section{Harm reduction}

Another way to reduce the harm of smoking could be through tobacco product modification [192, 193]. For those smokers not motivated to quit, smoking a less hazardous cigarette might be beneficial. Also, smokeless tobacco (chewing tobacco and snuff) might be an alternative to tobacco smoking, with reduced health risk compared with smoking [194]. 


\section{Implementation of smoking reduction}

The smoking reduction concept should be offered to patients with respiratory disorders who smoke and who are not motivated to quit. They should be prescribed NRT (nicotine gum or inhaler) for 3 months and recommended to reduce their number of cigarettes $\cdot$ day $^{-1}$ by $\geqslant 50 \%$ during the first $1-$ 2 weeks and then to try to reduce further. If the smoker has not reduced by $\geqslant 50 \%$ after 3 months, NRT should be stopped as the chance of subsequent quitting is low. In smokers who have reduced by $\geqslant 50 \%$ at 3 months, NRT should be continued for up to $1 \mathrm{yr}$, but after 6 months the patient should be recommended to try to stop smoking completely. The aim is that successfully reducing smoking will motivate this group of recalcitrant smokers to quit. However, to date the smoking reduction approach to cessation has only been tested in healthy smokers.

In summary, smoking reduction seems to have a role for smokers not currently motivated or able to quit as a gateway to complete cessation. There is limited evidence that smoking reduction per se is followed by an improvement in health.

\section{ORGANISATIONAL ANCHORAGE AND EDUCATION}

The above evidence and recommendations firmly place smoking cessation as an important and essential intervention in most patients with respiratory diseases. Smoking cessation services should be an integral part of a chest unit, in the same way as lung function testing and bronchoscopy, offering advice and help to all smokers with respiratory diseases independently of the smoker's motivation, but focusing primarily on those who want to try to quit. Smokers who are unable to quit should be supported to reduce smoking. As a minimum, chest departments should offer smoking cessation support, NRT and/or bupropion SR and at least four followup visits to all smokers. The precise details of each service are likely to depend on local factors and national differences, taking into account the fact that individual clinicians fail to intervene with more than one-third of smokers [9].

Smoking cessation can be performed individually or in groups, but manpower and time need to be integrated into the chest unit's staffing and clinic schedule, together with a budget for pharmacotherapy.

\section{Systematic identification of smokers}

Focusing on hospitals (either in-patients or outpatients), there should be an organisational plan for identifying smokers, documenting smoking data in patients' records and delivering brief advice with an offer of referral to the smoking cessation service $[9,195]$.

The US Agency for Health Care Policy and Research guideline [9] suggests that every medical setting should implement a system for identifying smokers. Meta-analysis of nine studies showed that the estimated intervention rate by clinicians with their patients who smoke increased from 39 to $66 \%$ (95\% CI 58$73 \%$ ) when a screening system was in place to identify smoking status. Regarding cessation rate, the impact of an identification system versus none $(n=3$ studies) reported estimated cessation rates of $6.4 \%(1.3-11.6 \%$ ) versus $3.1 \%$ (not significant), although these statistics are based on a small number of studies [9].

\section{Equipment and staffing}

Certain requirement and expertise should be available in each clinic unit to perform the assessments described above. It should be possible to assess $\mathrm{CO}$ level, nicotine dependence and motivation to quit $[80,196,197]$.

One or two staff members should be responsible for the smoking cessation programme, staff training, and management of the practical aspects. If the clinic cannot offer smoking cessation services, there should be written flowcharts stating where to refer the patients.

It is also important to engage GPs in smoking cessation, as many COPD patients consult their GP frequently.

\section{Education}

It has been difficult to demonstrate that guidelines alter clinical practice [198]. Education over a few days seems ineffective and multiple implementation tools are more effective than single ones. The following tools have been shown to alter physicians' behaviour [199]: Education by physician "opinion leaders"; computerised concurrent feedback on clinical decisions; academic detailing (i.e. one-on-one education, often by a pharmacist); and physician incentives, but also patient education or information and patient incentives.

Guidelines should be simple, pragmatic, usable and flexible with an increasing focus on implementation [198, 200].

Smoking cessation should be part of the core curriculum of the undergraduate and postgraduate education and training of physicians.

It is the current authors' experience that knowledge about smoking dependence and cessation varies among healthcare workers. There seems to be a need to update knowledge in this area among physicians, particularly about the available pharmacotherapy for smoking cessation. As smoking plays so large an aetiological role for a majority of pulmonary disorders, the pulmonary clinician's knowledge of smoking cessation must be at a level similar to their knowledge about other respiratory therapies, e.g. bronchodilators and inhaled steroids.

Formal training courses are needed to educate smoking cessation counsellors and courses must be repeated to take account of turnover among staff members. It would be optimal if all pulmonary clinicians participated in the above education. There should also be postgraduate smoking cessation courses at the annual ERS conference.

The personal smoking habits and attitudes towards smoking of chest physicians and healthcare staff do not appear to interfere with their ability to cope with smoking cessation, but advice to quit might be seen as less reliable by the patient [201].

\section{Smoke-free healthcare}

Smoking should be banned in hospitals, both for hospitalised and ambulatory patients and for staff. All hospitals in the USA went smoke-free a decade ago without severe problems. Europe is far behind. The most important value of smoke-free healthcare is the signal it gives patients, relatives and the community as a whole. For the individual smoker, the lung clinic might appear more trustworthy if it is "no smoking". 
Working in a smoke-free environment also avoids the adverse health effects of passive smoking.

When a smoker with respiratory disease is hospitalised in a smoke-free ward, this is an extra opportunity for intervention, independent of the patient's motivation to quit. The ward should support the smoker with advice and behavioural support from a smoking cessation counsellor, plus NRT or bupropion SR.

The European Smoke-Free Hospital Network consists of 16 member countries. This organisation has created implementation guidelines for turning a hospital smoke-free, as well as training guidelines and material for healthcare workers [202].

Also, some chest clinics could offer the local community expertise for training, education, research, advocacy and lobbying, as well as developing and testing new therapies.

\section{THE COSTS OF SMOKING AND ECONOMICS OF SMOKING CESSATION \\ Costs of smoking-related diseases}

One recent US study, considering the entire population of the USA, reported the annual difference in medical expenditure for people with smoking-related diseases compared with those without to be US\$6 billion [203]. In The Netherlands, when inflated to 1997 prices, the lifetime cost for smoking-related diseases for the entire population was estimated to be US $\$ 7.27$ billion for males and US\$9.47 billion for females [204]. These figures do not include the economic costs associated with lost working days caused by smoking-related morbidity or premature mortality.

A cost-of-illness study carried out in Germany [205], with figures expressed in 1996 values, estimated the total smokingrelated healthcare costs in 1996 for COPD to be $€ 5.471$ billion (attributable fraction due to smoking 73\%), lung cancer $€ 2.593$ billion $(89 \%)$, cancer of the mouth and larynx $€ 996$ million $(65 \%)$, stroke $€ 1.774$ billion (28\%), coronary artery disease $€ 4.963$ billion ( $35 \%$ ) and atherosclerotic occlusive disease $€ 761$ million $(28 \%)$. The total economic burden of smoking-related healthcare costs for Germany in 1996 was $€ 16.6$ billion.

The annual costs to the UK National Health Service (NHS) of adult smoking-related disease approach $€ 2.3$ billion [206, 207] in 1998 values. In 2000, costs related to lost working days in the UK due to smoking are estimated to be $€ 130$ billion; lung cancer is associated with $5.7 \%$ of all smoking-related NHS costs. Of the healthcare costs, $90 \%$ of lung cancer costs are from hospital rather than primary care [207].

Healthcare costs related to smoking were calculated for Italy as a contribution to the development of an international, deterministic population-based model termed Economic Consequences of Smoking (ECOS), endorsed by the WHO in line with the 1999 Action Plan for a Tobacco-Free Europe [208]. In 1998, the total burden of smoking-related healthcare costs for Italy was estimated to be $€ 4.31271$ billion (cardiovascular disease $€ 2.46419$ billion; COPD $€ 451.53$ million; small-cell lung cancer $€ 58.06$ million; nonsmall cell lung cancer $€ 232.25$ million; stroke $€ 1.10667$ billion) [209].

When non-healthcare-related costs are considered, losses from fires caused by smoking materials are estimated at $\sim € 6$ million $\cdot \mathrm{yr}^{-1}$ in Scotland [210] and $€ 218$ million $\cdot \mathrm{yr}^{-1}$ in England and Wales [207].

As far as costs related to loss of productivity are concerned, a recent Scottish survey showed absenteeism to be higher among smokers than nonsmokers [210]. The estimated cost of smoking-related absence in Scotland is $€ 60 \mathrm{million} \cdot \mathrm{yr}^{-1}$ [210], whereas total productivity losses are estimated at $\sim € 660$ million $\cdot \mathrm{yr}^{-1}$ [207].

\section{Cost-effectiveness of smoking cessation interventions}

Interventions aimed at stopping smoking are highly costeffective compared with other healthcare programmes. According to one of the most famous examples of league tables, directories of healthcare programmes ranked from the lowest to the highest cost per year of life [210] or, more often, per quality-adjusted life-year (QALY) gained [211-213], giving up smoking following a GP's advice (cost per QALY of $€ 400$ at 1990 prices) was considered good value for money and ranked third in a list of 21 medical and surgical interventions aimed at preventing or treating different diseases [213].

Among healthcare programmes aimed at COPD patients, when expressed in 1990-1991 prices, the cost per year of life gained following smoking cessation therapy was US\$6,500 [214], whereas the costs per year of life gained following a pulmonary rehabilitation programme or an $\alpha_{1}$-antitrypsin deficit therapy approach US\$24,300 and US\$50,000, respectively [215]. When expressed in 1997 prices, smoking cessation interventions are more cost-effective (US\$2,700 per year of life saved) than other healthcare programmes targeted at different diseases, such as mammography screening (US\$50,000 per year of life saved) and treatment of high cholesterol level (US $\$ 100,000$ per year of life saved) [216, 217].

According to one of the most important contributions on the cost-effectiveness of smoking cessation interventions carried out in the UK, the cost per year of life saved ranged from $€ 354$ (GP's brief advice to stop smoking) to $€ 1,458$ (GP's advice plus self-help plus advice to purchase NRT with specialist services), when inflated to 1998 prices. Even accepting that these figures were calculated when smoking cessation clinics were not operating (so that the second cost could be slightly higher) it is still a very economical intervention. All these figures included healthcare and non-healthcare resource-related cost [206, 207]. According to a UK cost-effectiveness model comparing different smoking cessation interventions from the NHS viewpoint, the incremental cost per life-years saved is $\sim € 1,500-3,500$ for NRT, €935-2,200 for bupropion SR and $€ 1,300-2,900$ for NRT plus bupropion SR [218]. As part of a set of guidelines on smoking cessation for Italian GPs, a costeffectiveness analysis was performed to compare two hypothetical interventions aimed at smoking cessation in a GP setting [219]. The selected alternatives were primary care (i.e. GP's advice about quitting smoking) and cessation clinic (i.e. GP's advice plus NRT). When inflated to 2000 prices, the healthcarerelated costs were $€ 87.18$ and $€ 266.89$ for primary care and cessation clinic, respectively. On the grounds of previous evidence [207], the effectiveness of primary care and cessation clinic considered in the model was $7 \%$ and $17 \%$, respectively. When compared to the option of doing nothing, the incremental cost-effectiveness ratio (the incremental cost of 
obtaining a quitting smoker versus a less costly and less effective alternative) was $€ 1,245.43$ for primary care and $€ 1,797.10$ for cessation clinic.

\section{Smoking cessation and financially better-off patients}

Because of certain social factors (such as living in a healthy environment, pursuing a good level of education, being aware that smoking is harmful), the better-off are probably less prone to becoming dependent on tobacco and more compliant than poorer people with interventions aimed at stopping smoking. According to an extensive enquiry into inequalities in health carried out in the UK [217, 220], the biggest reductions in smoking prevalence have been in the better-off, while in the least well-off there has been comparatively little benefit [221].

\section{Smoking cessation and price elasticity of current cigarette smokers}

Price elasticity (the expected reduction in cigarette consumption following an increase in cigarette price) is inversely related to smoker's age. US empirical research on this topic reported the lowest price elasticity (-0.095) among smokers aged 27$29 \mathrm{yrs}$ and the highest price elasticity (-0.831) among smokers aged 15-17 yrs [222].

The theory of rational addiction [223-225] may explain these results. It claims that smoking addiction, like a stock of capital, increases with time. Thus, the longer the duration of smoking addiction, the lower the probability that the smoker will give up following an increase in cigarette price. Again, the relevant role of cigarette price in preventing transition from experimental smoking (teenagers) to more regular smoking (adults) $[226,227]$ should be conveniently highlighted, since, quoting the above-mentioned results [222], an increase of $1 \%$ in cigarette price may result in a reduction in cigarette consumption of $0.83 \%$ among teenagers.

A recent study based on data from several European countries demonstrated that all first-line therapies for smoking cessation are highly cost-effective compared to other preventive interventions [228].

\section{Key points}

Due to wide differences in price elasticity and according to the theory of rational addiction, high cigarette taxes and prices play a role in reducing future smoking among teenagers, but less so among adult smokers.

Interventions aimed at smoking cessation show a low cost per QALY (or per year of life) gained. Enrolling low-income people, the poorly educated low-schooling population and manual workers who are addicted to tobacco in ad hoc smoking cessation programmes (e.g. workplace-delivered tobacco dissuasion sessions) will possibly increase the cost per QALY of these interventions at the start but could probably reduce to a greater extent the global prevalence of smokers in the future.

Among the currently available smoking cessation interventions, GP's or specialist's advice, NRT and bupropion SR seem to be good value for money. Owing to its cost-effectiveness, NRT was allowed on prescription in primary care in the UK from April 2001.

\section{RESEARCH PROSPECTS}

1) Examine the efficacy of nicotine replacement therapy and bupropion sustained release and combinations for smoking cessation in patients with respiratory diseases, particularly chronic obstructive pulmonary disease and asthma. Smoking cessation studies are also needed for smokers with several other respiratory disorders, such as tuberculosis, $\alpha_{1}$-antitrypsin deficiency, histiocytosis $\mathrm{X}$ and candidates for lung transplantation.

2) Examine the efficacy of different re-treatment interventions as well as long-term treatment for smoking cessation in patients with respiratory diseases.

3) Examine the efficacy of smokeless tobacco as a smoking cessation tool in recalcitrant smokers.

4) Examine the efficacy of lung-function screening in asymptomatic and symptomatic smokers, combined with different smoking cessation approaches.

5) Explore the characteristics of tobacco dependence/nicotine addiction and barriers and motivation to quit in patients with respiratory diseases.

6) Examine whether reduced smoking in patients not motivated to give up can increase self- confidence and motivation to quit.

7) Examine the relationship between chronic obstructive pulmonary disease and depression and evaluate whether treatment for depression can help dependent respiratory patients to quit.

8) Evaluate the efficacy of new drugs for smoking cessation in respiratory patients.

9) Evaluate the efficacy of smoking cessation programmes in rehabilitation courses.

10) Evaluate the efficacy of internet-based programmes, quitlines and other "mass-media" methods for smoking cessation.

\section{ACKNOWLEDGEMENTS}

The authors would like to thank F. Pistelli, Cardiopulmonary Dept, University Hospital of Pisa, and A. Scognanuglio, Pulmonary Environmental Epidemiology Unit, CRN Institute of Clinical Physiology, Pisa for their contribution to several parts of this report.

\section{REFERENCES}

1 Postma DS, Siafakas NM, eds. Management of Chronic Obstructive Pulmonary Disease. Eur Respir Mon 1998; 7.

2 Global Initiative for Chronic Obstructive Lung disease. NHLBI/WHO Workshop. US Dept of Health and Human Services, National Institutes of Health, National Heart, Lung and Blood Institute. NIH Publication No. 2701A. Bethesda, National Institutes of Health, 2001.

3 Fletcher C, Peto R. The natural history of chronic airflow obstruction. BMJ 1977; 1: 1645-1648.

4 Fletcher C, Peto R, Tinker C, Speizer FE, eds. The natural history of chronic bronchitis and emphysema. Oxford, Oxford University Press, 1976.

5 Anthonisen NR, Connett JE, Kiley JP, et al. Effects of smoking intervention and the use of an inhaled anticholinergic bronchodilator on the rate of decline of FEV1. The Lung Health Study. JAMA 1994; 272: 1497-1505. 
6 Hand S, Edwards S, Campbell IA, Cannings R. Controlled trial of three weeks nicotine replacement in hospital patients also given advice and support. Thorax 2002; 57: 715-718.

7 Borson S, Claypoole K, McDonald GJ. Depression and chronic obstructive pulmonary disease: treatment trials. Semin Clin Neuropsychiatry 1998; 3: 115-130.

8 Tashkin DP, Kanner R, Bailey W, et al. Smoking cessation in patients with chronic obstructive pulmonary disease: a double-blind, placebo-controlled, randomised trial. Lancet 2001; 357: 1571-1575.

9 Fiore MC, Bailey WC, Cohen SJ, et al. Smoking cessation: clinical practice guidelines No. 18. Public Health Service, Agency for Health Care Policy and Research. AHCPR Publication No. 96-0692. Rockville, US Dept of Health and Human Services, 1996.

10 Fiore M, Bailey W, Cohen S, et al. Treating tobacco use and dependence: clinical practice guideline. Rockville, US Dept of Health and Human Services, 2000.

11 The Tobacco Use and Dependence Clinical Practice Guideline Panel, Staff and Consortium Representatives. A clinical practice guideline for treating tobacco use and dependence: a US Public Health Service report. JAMA 2000; 283: 3244-3254.

12 Anderson JE, Jorenby DE, Scott WJ, Fiore MC. Treating tobacco use and dependence: an evidence-based clinical practice guideline for tobacco cessation. Chest 2002; 121: 932-941.

13 American College of Chest Physicians, American Thoracic Society, European Respiratory Society, Asian Pacific Society of Respirology, Canadian Thoracic Society, International Union Against Tuberculosis and Lung Disease. Smoking and health: the physician's responsibility. A statement by the Health and Smoking Committee. Pneumologie 1996; 50: 270-274.

14 Hughes JR, Fiester S, Goldstein MG, Resnick MP, Rock N, Ziedonis D. The American Psychiatric Association Practice Guidelines for the treatment of patients with nicotine dependence. Am J Psychiatry 1996; 153: Suppl. 10, S1-S31.

15 Haustein KO. Tobacco or Health? Berlin, SpringerVerlag, 2001; pp. 34-43.

16 Batra V, Patkar AA, Berrettini WH, Weinstein SP, Leone FT. The genetic determinants of smoking. Chest 2003; 123: 1730-1739.

17 Watkins SS, Koob GF, Markou A. Neural mechanisms underlying nicotine addiction: acute positive reinforcement and withdrawal. Nicotine Tob Res 2000; 2: 19-37.

18 US Department of Health and Human Services. Nicotine addiction. A report of the Surgeon General. Rockville, US Dept of Health and Human Services, 1998.

19 World Health Organization. International Classification of Diseases, 10th Edn. Geneva, World Health Organization, 1992.

20 American Psychiatric Association. Diagnostic and statistical manual of mental disorders, 4th Edn. Washington, American Psychiatric Association, 1994.

21 Hughes JR, Gust SW, Skoog K, Keenan RM, Fenwick JW. Symptoms of tobacco withdrawal. A replication and extension. Arch Gen Psychiatry 1991; 48: 52-59.
22 Shiffman S, West RJ, Gilbert DG. SRNT Work Group on the Assessment of Craving and Withdrawal in Clinical trials. Nicotine Tob Res 2004; 6: 599-614.

23 The World Bank. Curbing the Epidemic: Governments and the Economics of Tobacco Control. Washington, The World Bank, 1999. Available at www1.worldbank.org/ tobacco/reports.asp. Date last accessed: March 15, 2005. Date last updated: 2001.

24 Tobacco Policy in the European Union: ASH Fact Sheet No. 20. www.ash.org.uk/html/factsheets/html/fact20. html. Date last accessed: November 28, 2005. Date last updated: May 2006.

25 Doxa. Indagine sul fumo in Italia 2004. www.doxa.it/ italiano/inchieste/fumo2004_ita.pdf. Date last accessed: March 15, 2005. Date last updated: April 2004.

26 Murin S, Bilello KS, Matthay R. Other smoking-affected pulmonary diseases. Clin Chest Med 2000; 21: 121-137.

27 US Department of Health and Human Services. The health consequences of smoking: a report of the Surgeon General, 2004. www.cdc.gov/tobacco/sgr/sgr_2004/ index.htm. Date last accessed: November 28, 2006. Date last updated: February 15, 2006.

28 Peto R, Lopez AD, Boreham J, Thun M, Heath C Jr., Doll R. Mortality from smoking worldwide. Br Med Bull 1996; 52: 12-21.

29 Ezzati M, Lopez AD. Estimates of global mortality attributable to smoking in 2000. Lancet 2003; 362: 847-852.

30 Rodu B, Cole P. The burden of mortality from smoking: comparing Sweden with other countries in the European Union. Eur J Epidemiol 2004; 19: 129-131.

31 Doll R, Peto R, Boreham J, Sutherland I. Mortality in relation to smoking: 50 years' observations on male British doctors. BMJ 2004; 328: 1529-1533.

32 Lung cancer. In: European Respiratory Society/European Lung Foundation. European Lung White Book. The First Comprehensive Survey on Respiratory Health in Europe. Sheffield, ERS Journals, 2003; pp. 44-54.

33 La Vecchia C, Franceschi S, Levi F. Epidemiological research on cancer with a focus on Europe. Eur J Cancer Prev 2003; 12: 5-14.

34 Alberg AJ, Samet JM. Epidemiology of lung cancer. Chest 2003; 123: Suppl. 1, 21S-49S.

35 Flanders WD, Lally CA, Zhu BP, Henley SJ, Thun MJ. Lung cancer mortality in relation to age, duration of smoking, and daily cigarette consumption: results from Cancer Prevention Study II. Cancer Res 2003; 63: 6556-6562.

36 Simonato L, Agudo A, Ahrens W, et al. Lung cancer and cigarette smoking in Europe: an update of risk estimates and an assessment of inter-country heterogeneity. Int J Cancer 2001; 91: 876-887.

37 Murray CJL, Lopez AD. Alternative projections of mortality and disability by cause 1990-2020: Global Burden of Disease Study. Lancet 1997; 349: 1498-1504.

38 Chronic obstructive pulmonary disease. In: European Respiratory Society/European Lung Foundation. European Lung White Book. The First Comprehensive Survey on Respiratory Health in Europe. Sheffield, ERS Journals, 2003; pp. 34-43.

39 Burney P, Suissa S, Soriano JB, et al. The pharmacoepidemiology of COPD: recent advances and methodological discussion. Eur Respir J 2003; 22: Suppl. 42, 1s-44s. 
40 Wedzicha JA, Donaldson GC. Exacerbations of chronic obstructive pulmonary disease. Respir Care 2003; 48: 1204-1213.

41 Viegi G, Pedreschi M, Baldacci S, et al. Prevalence rates of respiratory symptoms and diseases in general population samples of North and Central Italy. Int J Tuberc Lung Dis 1999; 3: 1034-1042.

42 Lundback B, Lindberg A, Lindstrom M, et al. Obstructive lung disease in Northern Sweden studies. Not 15 but $50 \%$ of smokers develop COPD? Report from the Obstructive Lung Disease in Northern Sweden Studies. Respir Med 2003; 97: 115-122.

43 de Marco R, Accordini S, Cerveri I, et al., for the European Community Respiratory Health Survey (ECRHS) Study Group. An international survey of chronic obstructive pulmonary disease in young adults according to GOLD stages. Thorax 2004; 59: 120-125.

44 Jimenez-Ruiz CA, Masa F, Miravittles M, et al. Differences in attitudes and dependence between healthy smokers and smokers with COPD. Chest 2001; 119: 1365-1370.

45 Watson L., Boezen HM., Postma DS. Differences between males and females in the natural history of asthma and COPD. In: Buist S, Mapp CE, eds. Respiratory Diseases in Women. Eur Respir Mon 2003; 25: 50-73.

46 Viegi G, Scognamiglio A, Baldacci S, Pistelli F, Carrozzi L. Epidemiology of chronic obstructive pulmonary disease (COPD). Respiration 2001; 68: 4-19.

47 Calverley PMA, Walker P. Chronic obstructive pulmonary disease. Lancet 2003; 362: 1053-1061.

48 Willemse BWM, Postma DS, Timens W, ten Hacken NHT. The impact of smoking cessation on respiratory symptoms, lung function, airway hyperresponsiveness and inflammation. Eur Respir J 2004; 23: 464-476.

49 Anthonisen NR, Skeans MA, Wise RA, Manfreda J, Kanner RE, Connett JE, for the Lung Health Study Research Group. The effects of a smoking cessation intervention on 14.5-year mortality. Ann Intern Med 2005; 142: 233-239.

50 Cerveri I, Accordini S, Corsico A, et al., for the ISAYA Study Group. Chronic cough and phlegm in young adults. Eur Respir J 2003; 22: 413-417.

51 Carrozzi L, Rijcken B, Burney P, et al. Family history for chronic lung diseases and epidemiological determinants of COPD in three European countries. Eur Respir Rev 2001; 11: 49-54.

52 Eagan TML, Gulsvik A, Eide GE, Bakke PS. Remission of respiratory symptoms by smoking and occupational exposure in a cohort study. Eur Respir J 2004; 23: 589-594.

53 Kerstjens HAM, Rijcken B, Schouten JP, Postma DS. Decline of FEV1 by age and smoking status: facts, figures, and fallacies. Thorax 1997; 52: 820-827.

54 Gold DR, Wang X, Wypij D, Speizer FE, Ware JH, Dockery DW. Effects of cigarette smoking on lung function in adolescent boys and girls. $N$ Engl J Med 1996; 335: 931-937.

55 Sherrill DL, Lebowitz MD, Knudson RJ, Burrows B. Smoking and symptom effects on the curves of lung function growth and decline. Am Rev Respir Dis 1991; 144: $17-22$.
56 Xu X, Weiss ST, Rijcken B, Schouten JP. Smoking, changes in smoking habits, and rate of decline in FEV1: new insight into gender differences. Eur Respir J 1994; 7: 1056-1061.

57 Downs SH, Brandli O, Zellweger JP, et al. Accelerated decline in lung function in smoking women with airway obstruction: SAPALDIA 2 cohort study. Respir Res 2005; 6: 45 .

58 Anthonisen NR, Connett JE, Murray RP. Smoking and lung function of Lung Health Study participants after 11 years. Am J Respir Crit Care Med 2002; 166: 675-679.

59 Scanlon PD, Connett JE, Waller LA, Altose MD, Bailey WC, Buist AS. Smoking cessation and lung function in mild-to-moderate chronic obstructive pulmonary disease. The Lung Health Study. Am J Respir Crit Care Med 2000; 161: 381-390.

60 Sherrill DL, Enright P, Cline M, Burrows B, Lebowitz MD. Rates of decline in lung function among subjects who restart cigarette smoking. Chest 1996; 109: 1001-1005.

61 Murray RP, Anthonisen NR, Connett JE, et al. Effects of multiple attempts to quit smoking and relapses to smoking on pulmonary function. Lung Health Study Research Group. J Clin Epidemiol 1998; 51: 1317-1326.

62 Bolliger CT, Zellweger JP, Danielsson T, et al. Influence of long-term smoking reduction on health risk markers and quality of life. Nicotine Tob Res 2002; 4: 433-439.

63 Viegi G, Paoletti P, Carrozzi L, et al. CO diffusing capacity in a general population sample: relationships with cigarette smoking and airflow obstruction. Respiration 1993; 60: 155-161.

64 Viegi G, Sherrill DL, Carrozzi L, et al. An 8-year followup of carbon monoxide diffusing capacity in a general population sample of northern Italy. Chest 2001; 120: 74-80.

65 Viegi G, Matteelli G, Annesi I. Epidemiology of asthma. In: Chung F, Fabbri LM, eds. Asthma. Eur Respir Mon 2003; 23: 1-25.

66 Ulrik CS, Lange P. Cigarette smoking and asthma. Monaldi Arch Chest Dis 2001; 56: 349-353.

67 Thomson NC, Chaudhuri R, Livingston E. Asthma and cigarette smoking. Eur Respir J 2004; 24: 822-833.

68 Doll R. Risk from tobacco and potentials for health gain. Int J Tuberc Lung Dis 1999; 3: 90-99.

69 Tønnesen P, Pisinger C, Hvidberg S, et al. Effects of smoking cessation and reduction in asthmatics. Nicotine Tob Res 2005; 7: 139-148.

70 Farr BM, Bartlett CL, Wadsworth J, Miller DL. Risk factors for community-acquired pneumonia diagnosed upon hospital admission. British Thoracic Society Pneumonia Study Group. Respir Med 2000; 94: 954-963.

71 Almirall J, Gonzalez CA, Balanzo X, Bolibar I. Proportion of community-acquired pneumonia cases attributable to tobacco smoking. Chest 1999; 116: 375-379.

72 Nuorti JP, Butler JC, Farley MM, et al. Cigarette smoking and invasive pneumococcal disease. Active Bacterial Core Surveillance Team. N Engl J Med 2000; 342: 681-689.

73 Arcavi L, Benowitz NL. Cigarette smoking and infection. Arch Intern Med 2004; 164: 2206-2216.

74 Gajalakshmi V, Peto R, Kanaka TS, Jha P. Smoking and mortality from tuberculosis and other diseases in India: 
retrospective study of 43000 adult male deaths and 35 000 controls. Lancet 2003; 362: 507-515.

75 Baumgartner KB, Samet JM, Stidley CA, Colby TV, Waldron JA, Collaborating Centers. Cigarette smoking: a risk factor for idiopathic pulmonary fibrosis. Am J Respir Crit Care Med 1997; 155: 242-248.

76 Chiyo M, Sekine Y, Iwata T, et al. Impact of interstitial lung disease on surgical morbidity and mortality for lung cancer: analyses of short-term and long-term outcomes. J Thorac Cardiovasc Surg 2003; 126: 1141-1146.

77 Henry M, Arnold T, Harvey J, on behalf of the BTS Pleural Disease Group, a subgroup of the BTS Standards of Care Committee. BTS guidelines for the management of spontaneous pneumothorax. Thorax 2003; 58: Suppl. II, 39-52.

78 Rollnick S, Mason P, Butler C. Health behaviour change: a guide for practitioners. London, Churchill Livingstone, 1999.

79 Fagerström KO. Time to first cigarette; the best single indicator of tobacco dependence. Monaldi Arch Chest Dis 2003; 59: 95-98.

80 Etter JF, Duc TV, Perneger TV. Saliva cotinine levels in smokers and non-smokers. Am J Epidem 2000; 151: 251-258.

81 Heatherton TF, Kozlowski LT, Frecker RC, Fagerström KO. The Fagerström Test for Nicotine Dependence: a revision of the Fagerström Tolerance Questionnaire. British Journal of Addiction 1991; 86: 1119-1127.

82 Fagerström KO, Schneider N. Measuring nicotine dependence: A review of the Fagerström Tolerance Questionnaire. J Behav Med 1989; 12: 159-182.

83 Breslau N, Johnson EO. Predicting smoking cessation and major depression in nicotine dependent smokers. Am J Pub Health 1999; 90: 1122-1127.

84 Batra A, Gelfort G, Bartels M. The dopamine D2 receptor (DRD2) gene - a genetic risk factor in heavy smoking? Addict Biol 2000; 5: 431-438.

85 Etter JF, LeHouezec J, Perneger TV. A self-administered questionnaire to measure addiction to cigarettes. The Cigarette Dependence Scale. Neuropsychopharmacology 2003; 28: 359-370.

86 Javors MA, Hatch JP, Lamb R. Cut-off levels for breath carbon monoxide as a marker for cigarette smoking. Addiction 2005; 100: 159-167.

87 Jimenez-Ruiz CA, Masa F, Miravitlles M, et al. Smoking characteristics: differences in attitudes and dependence between healthy smokers and smokers with COPD. Chest 2001; 119: 1365-1370.

88 Petty TL, Doherty DE. National Lung Health Education Program. The National Lung Health Education Program: roots, mission, future directions. Respir Care 2004; 49: 678-683.

89 Enright PL, Kaminsky DA. Strategies for screening for chronic obstructive pulmonary disease. Respir Care 2003; 48: 1194-1201.

90 Clotet J, Gomez-Arbones X, Ciria C, Aldalad JM. Spirometry is a good method for detecting and monitoring chronic obstructive pulmonary disease in high-risk smokers in primary care. Arch Bronconeumol 2004; 40: 155-159.

91 Stratelis G, Jakobsson P, Molstad S, Zetterstrom O. Early detection of COPD in primary care: screening by invitation of smokers aged 40 to 55 years. Brit J Gen Pract 2004; 54: 201-206.

92 Gorecka D, Bednarek M, Nowinski A, Puscinska E, Goljan-Geremek A, Zielinski J. Diagnosis of airflow limitation combined with smoking cessation advice increases stop-smoking rate. Chest 2003; 123: 1916-1923.

93 Bize R, Burnand B, Mueller Y, Cornuz J. Biomedical risk assessment as an aid for smoking cessation. Cochrane Database Syst Rev 2005; 4: CD0004705.

94 Hughes JR. Comorbidity and smoking. Nicotine Tob Res 1999; 1: Suppl. 2, S149-S152.

95 Dierker LC, Avenevoli S, Stolar M, Merikangas KR. Smoking and depression: an examination of mechanisms of comorbidity. Am J Psychiatry 2002; 159: 947-953.

96 Glassman AH, Covey LS, Stetner F, Rivelli S. Smoking cessation and the source of major depression: a follow up study. Lancet 2001; 357: 1929-1932.

97 Wagena E, Kant I, Huibers MJ, et al. Psychological distress and depressed mood in employees with asthma, chronic bronchitis or emphysema: a population-based observational study on prevalence and the relationship with smoking cigarettes. Eur J Epidemiol 2004; 19: 147-153.

98 Arrol B, Khin N, Kerse N. Screening for depression in primary care with two verbally asked questions: cross sectional study. BMJ 2003; 327: 1144-1146.

99 Watkins C, Daniels L, Jack C, Dickinson H, van der Broek M. Accuracy of a single question in screening for depression in a cohort of patients after stroke: comparative study. BMJ 2001; 323: 1159.

100 Centers for Disease Control and Prevention. Smoking cessation during previous years among adults in United States 1990 and 1991. MMWR 1993; 42: 504-507.

101 US Dept of Health and Human Services. The health consequences of smoking: Chronic obstructive lung disease. A report of the Surgeon General. Rockville, US Dept of Health and Human Services, 1984.

102 van Manen JG, Bindels PJ, Dekker FW. Risk of depression in patients with chronic obstructive pulmonary disease and its determinants. Thorax 2002; 57: 412-416.

103 Wagena EJ, Kant I, van Amelsvoort LG, Wouters EF, van Schaychk CP, Swaen GM. Risk of depression and anxiety in employees with chronic bronchitis: the modifying effect of cigarette smoking. Psychosom Med 2004; 5: 729-734.

104 Breslau N, Peterson EL, Schultz LR. Major depression and stages of smoking. A longitudinal investigation. Arch Gen Psychiatry 1998; 55: 161-166.

105 Covey LS, Glassaman AH, Stetner F. Cigarette smoking and major depression. J Addict Dis 1998; 17: 35-46.

106 West R, Hajek P, Belcher M. Severity of withdrawal symptoms as a predictor of outcome of an attempt to quit smoking. Psychol Med 1989; 19: 981-985.

107 Shiffman S, Hickcox M, Paty J, Gnys M, Kassel J, Richards T. Progression from a smoking lapse to relapse: prediction from abstinence violation effects, nicotine dependence, and lapse characteristics. J Consult Clin Psychol 1996; 64: 993-1002.

108 Kim HF, Kunik ME, Molinari VA. Functional impairment in COPD patients: the impact of anxiety and depression. Psychosomatics 2000; 41: 465-471. 
109 de Voogd JN, Elzen HA. Psychological state and personality traits of patients in a pulmonary rehabilitation program. Eur Respir J 2001; 18: Suppl. 33, 54s.

110 Dudley DL, Wermuth C, Hague W. Psychological aspects of care in the chronic obstructive pulmonary disease patient. Heart Lung 1973; 2: 339-345.

111 Gorecka D, Bednarek M, Nowinski A, Plywaczewski R, Zielinski J, Bielen P. Nicotine dependence in smokers at risk for COPD. Eur Respir J 2002; 20: Suppl. 38, 134s.

112 Miloskovic V, Lazic Z. Lung function and level of the smoker's nicotine dependence. Eur Respir J 2001; 18: Suppl. 33, S115-S116.

113 Kunze U, Schoberberger R, Schmeiser-Rieder A, Fagerström K. Preventive oncology and nicotine addiction. In: Antypas G, ed. International Proceedings Division, 2nd International Congress on Lung Cancer. Bologna, Monduzzi Editore, 1996; pp. 551-554.

114 Mikami I, Akechi T, Kugaya A, et al. Screening for nicotine dependence among smoking-related cancer patients. Japan J Cancer Res 1999; 90: 1071-1075.

115 Jimenez-Ruiz CA, Miravitlles M, Sobradillo V, et al. Can cumulative tobacco consumption, FTND score, and carbon monoxide concentrations in expired air be predictors of chronic obstructive pulmonary disease? Nic Tob Res 2004; 6: 649-653.

116 Medici TC, Unger S, Ruegger M. Smoking pattern of smokers with and without tobacco-related lung diseases. Amer Rev Resp Dis 1985; 131: 385-388.

117 Pauwels RA, Buist AS, Calverley PM. Global strategy for the diagnosis, management, and prevention of chronic obstructive pulmonary disease. NHLBI/WHO Global Initiative for Chronic Obstructive Lung Disease (GOLD) Workshop Summary. Am J Respir Crit Care Med 2001; 163 : 1256-1276.

118 Siafakas NM, Vermeire P, Pride NB, et al. Optimal assessment and management of COPD. Eur Respir J 1995; 8: 1398-1420.

119 Gray-Donald K, Gibbons L, Shapiro SH, Macklem PT, Martin JG. Nutritional status and mortality in chronic obstructive pulmonary disease. Am J Respir Crit Care Med 1996; 153: 961-966.

120 Filozof C, Fernadez Pinilla MC, Fernadez-Cruz A. Smoking cessation and weight gain. Obes Rev 2004; 5: 95-103.

121 Lancaster T, Stead LF. Self-help interventions for smoking cessation. Cochrane Database Syst Rev 2005; 3: CD001118.

122 Borland R, Balmford J, Hunt D. The effectiveness of personally tailored computer generated advice letters for smoking cessation. Addiction 2004; 99: 369-377.

123 Quist-Paulsen P, Gallefos F. Randomised controlled trial of smoking cessation intervention after admission for coronary heart disease. BMJ 2003; 327: 1254-1257.

124 Aveyard P, Griffin C, Lawrence T, Cheng KK. A controlled trial of an expert system and self-help manual intervention based on the stages of change versus standard self-help materials in smoking cessation. Addiction 2003; 98: 345-354.

125 Lancaster T, Stead L. Physician advice for smoking cessation. Cochrane Database Syst Rev 2004; 4: CD000165.
126 Rice V, Stead LF. Nursing interventions for smoking cessation. Cochrane Database Syst Rev 2004; 1: CD001188.

127 British Thoracic Society. Comparison of four methods for smoking cessation in patients with smoking related disorders. BMJ 1983; 286: 595-597.

128 Lancaster T, Stead LF. Individual behavioural counselling for smoking cessation. Cochrane Database Syst Rev 2005; 2: CD001292.

129 Stead LF, Lancaster T. Group behaviour therapy programmes for smoking cessation. Cochrane Database Syst Rev 2005; 2: CD001007.

130 Lichtenstein E, Glasgow RE, Lando HA, Ossip-Klein DJ, Boles SM. Telephone counseling for smoking cessation: rationales and meta-analytic review of evidence. Health Educ Res 1996; 11: 243-257.

131 Stead LF, Lancaster T, Perera R. Telephone counselling for smoking cessation. Cochrane Database Syst Rev 2006; 3: CD002850.

132 Borland R, Segan CJ, Livingston PM, Owen N. The effectiveness of callback counselling for smoking cessation: a randomised trial. Addiction 2001; 96: 881-889.

133 Macleod ZR, Charles MA, Arnaldi VC, Adams IM. Telephone counselling as an adjunct to nicotine patches in smoking cessation: a randomised controlled trial. Med J Aust 2003; 179: 349-352.

134 Hajek P, Stead LF. Aversive smoking for smoking cessation. Cochrane Database Syst Rev 2001; 3: CD000546.

135 Ussher M, Nunciata P, Cropley M, West R. Effect of a short bout of exercise on tobacco withdrawal symptoms and desire to smoke. Psychopharmacology (Berl) 2001; 158: 66-72.

136 Bock BC, Marcus BH, King TK, Borrelli B, Roberts MR. Exercise effects on withdrawal and mood among women attempting smoking cessation. Addict Behav 1999; 24: 399-410.

137 Steptoe A, Edwards S, Moses J, Mathews A. The effects of exercise training on mood and perceived coping ability in anxious adults from the general population. J Psychosom Res 1989; 33: 537-547.

138 McAuley E, Mihalko SL, Bane SM. Exercise and selfesteem in middle-aged adults: multidimensional relationships and physical fitness and self-efficacy influences. $J$ Behav Med 1997; 20: 67-83.

139 Ussher M. Exercise interventions for smoking cessation. Cochrane Database Syst Rev 2005; 1: CD002295.

140 Silagy C, Lancaster T, Stead L, Mant D, Fowler G. Nicotine replacement therapy for smoking cessation. Cochrane Database Syst Rev 2004; 3: CD000146.

141 Hughes JR, Stead LF, Lancaster T. Antidepressants for smoking cessation. Cochrane Database Syst Rev 2004; 4: CD000031.

142 Crowley TJ, Macdonald MJ, Walter MI. Behavioural antismoking trial in chronic obstructive pulmonary disease patients. Psychopharmacology 1995; 119: 193-204.

143 Pederson LL, Wanklin JM, Lefcoe NM. The effect of counselling on smoking cessation among patients hospitalised with chronic obstructive pulmonary disease: a randomised clinical trial. Int J Addiction 1991; 26: 107-119.

144 Wagena EJ, van der Meer RM, Ostelo RJ, Jacobs JE, van Schayck CP. The efficacy of smoking cessation strategies in people with chronic obstructive pulmonary disease: 
results from a systematic review. Respir Med 2004; 98: 805-815.

145 Research Committee of the British Thoracic Society. Smoking cessation in patients: two further studies by the British Thoracic Society. Thorax 1990; 45: 835-840.

146 Tønnesen P, Mikkelsen KL. Routine smoking cessation with four nicotine regiments in a lung clinic. Eur Respir J 2000; 16: 717-722.

147 West R, McNeill A, Raw M. Smoking cessation guidelines for health professionals: an update. Thorax 2000; 55: 987-999.

148 World Health Organisation. European partnership to reduce tobacco dependence: WHO evidence based recommendations on the treatment of tobacco dependence. Geneva, WHO, 2001.

149 National Institute for Health and Clinical Excellence. Smoking cessation - bupropion and nicotine replacement therapy. National Institute for Health and Clinical Excellence Technology appraisal TA39. www.nice. org.uk/page.aspx?o=TA39. Date last accessed: May 2006. Date last updated: March 2002.

150 Andersson JE, Jorenby DE, Scott WJ, Fiore MC. Treating tobacco use and dependence. Chest 2002; 121: 932-941.

151 Wagena E, Zeegers M, Van Schayck C, Wouters E. Benefits and risks of pharmacological smoking cessation therapies in chronic obstructive pulmonary disease. Drug Saf 2003; 26: 381-403.

152 Anthonisen NR, Connett JE, Kiley JP, et al. Effects of smoking intervention and the use of an inhaled anticholinergic bronchodilator on the rate of decline of FEV1: The Lung Health Study. JAMA 1994; 272: 1497-1505.

153 Sachs DPL, Benowitz NL, Silver KJ. Effective use of nicotine polacrilex (Nicorette) in patients with chronic obstructive pulmonary disease. In: Aoki M, Hisamichi S, Tominaga S, eds. Smoking and health. Amsterdam, Elsevier, 1987; pp. 793-795.

154 Glover ED, Glover PN, Abrons HL, et al. Smoking cessation among COPD and chronic bronchitis patients using the nicotine nasal spray. Am J Health Behav 1997; 21: 310-317.

155 Tønnesen P. Smoking cessation. In: Pauwels RA, Postma DS, Weiss ST, eds. Long-term intervention in chronic obstructive pulmonary disease. Lung Biology in Health and Disease, vol. 191. New York, Marcel Dekker, 2005; pp. 315-352.

156 Campell IA, Prescott RJ, Tjeder-Burton SM. Smoking cessation in hospital patients given repeated advice plus nicotine or placebo chewing gum. Respir Med 1991; 85: 155-157.

157 Campbell IA, Prescott RJ, Teder-Burton SM. Transdermal nicotine plus support in patients attending hospital with smoking-related diseases: a placebo-controlled study. Respir Med 1996; 90: 47-51.

158 Miller NH, Smith PM, DeBusk RF, Sobel DS, Taylor CB. Smoking cessation in hospitalized patients: results of a randomized trial. Arch Intern Med 1997; 157: 409-415.

159 Lewis SF, Piasecki TM, Anderson JE, Baker TB. Transdermal nicotine replacement for hospitalized patients: a randomized clinical trial. Prev Med 1998; 27: 296-303.
160 Tønnesen P, Mikkelsen KL, Markholst C, et al. Nurseconducted smoking cessation with minimal intervention in a lung clinic: a randomized controlled study. Eur Respir J 1996; 9: 2351-2355.

161 Tønnesen P, Mikkelsen K, Bremann L. Nurse-conducted smoking cessation in patients with COPD, using nicotine sublingual tablets and behavioral support. Chest 2006; 130: 314-316.

162 Gratziou C, Francis K, Maragianni A, et al. Bupropion treatment and cognitive behavioral therapy in smoking cessation program. Eur Respir J 2001; 18: Suppl. 33, 12s.

163 Richmond R, Zwar N. Review of bupropion for smoking cessation. Drug and Alcohol Review 2003; 22: 203-220.

164 Tønnesen P, Fryd V, Hansen M, et al. Two and four mg nicotine chewing gum and group counseling in smoking cessation: An open, randomized, controlled trial with a 22 month follow-up. Addict Behav 1988; 13: 17-27.

165 Tønnessen P, Paoletti P, Gustavsson G, et al. Higher dosage nicotine patches increase one-year smoking cessation rates: results from the European CEASE-trial. Eur Respir J 1999; 13: 238-246.

166 Shiffman S, Dressler C, Hajek P, Gilburt S, Targett D, Strahs K. Efficacy of a nicotine lozenge for smoking cessation. Arch Intern Med 2002; 162: 1267-1276.

167 Ferry LH, Burchette RJ. Efficacy of bupropion for smoking cessation in non-depressed smokers. J Addict Disord 1994; 13: 249.

168 Dalsgareth O, Hansen N, Soes-Petersen U, et al. A multicentre, randomised, double blind, placebo controlled, 6-month trial of bupropion hydrochloride sustained release tablets as an aid to smoking cessation in hospital employees. Nicotine Tob Res 2004; 6: 55-61.

169 Garcia-Rio F, Serrano S, Mediano O, Alonso A, Vilamor J. Safety profile of bupropion for COPD. Lancet 2001; 358: 1009-1010.

170 Tonstad S, Farsang D, Klaene G, et al. Bupropion SR for smoking cessation in smokers with cardiovascular disease: a multicentre, randomised study. Eur Heart J 2003; 24: 946-955.

171 Hays JT, Hurt RD, Rigotti NA, et al. Sustained-release bupropion for pharmacologic relapse prevention after smoking cessation: a randomized, controlled trial. Ann Intern Med 2001; 135: 423-433.

172 Sampablo I, Lores L, Coll-Klein F, Jimenez C, Rebasa P. Predictive factors in smoking cessation with combined therapy with bupropion and nicotine patches. Monaldi Arch Chest Dis 2003; 59: 171-176.

173 Jorenby DE, Leischow SJ, Nides MA, et al. A controlled trial of sustained-release bupropion, a nicotine patch, or both for smoking cessation. N Engl J Med 1999; 340: 685-691.

174 Glassman AH, Covey LS, Dalack GW, et al. Smoking cessation, clonidine, and vulnerability to nicotine among dependent smokers. Clin Pharmacol Ther 1993; 54: 670-679.

175 Hilleman DE, Mohiuddin SM, Delcore MG, Lucas BD Jr. Randomized controlled trial of transdermal clonidine for smoking cessation. Ann Pharmacother 1993; 27: 1025-1028.

176 Gonzales D, Rennard SI, Nides M, et al. Varenicline, an $\alpha_{4} \beta_{2}$ nicotinic acetylcholine receptor partial agonist, vs sustained-release bupropion and placebo for smoking cessation. JAMA 2006; 296: 47-55. 
177 Jorenby DE, Hays T, Rigotti NA, et al. Efficacy of varenicline, an $\alpha_{4} \beta_{2}$ nicotinic acetylcholine receptor partial agonist, $v$ s placebo or sustained-release bupropion for smoking cessation. JAMA 2006; 296: 56-63.

178 Tonstad S, Tønnesen P, Hajek P, et al. Effect of maintenance therapy with varenicline on smoking cessation. JAMA 2006; 296: 64-71.

179 Cohen C, Kodas E, Griebel G. $\mathrm{CB}_{1}$ receptor antagonists for the treatment of nicotine addiction. Pharmacol Biochem Behav 2005; 81: 387-395.

180 Anthenelli RM, Despres JP. Effects of rimonabant in the reduction of major cardiovascular risk factors. Results from the STRATUS-US Trial (smoking cessation in smokers motivated to quit). American College of Cardiology 53rd Annual Scientific Session. New Orleans, American College of Cardiology, 2004.

181 Van Gaal LF, Rissanen AM, Scheen AJ, Ziegler O, Rossner S. Effects of the cannabinoid-1 receptor blocker rimonabant on weight reduction and cardiovascular risk factors in overweight patients: 1-year experience from the RIO-Europe study. Lancet 2005; 365: 1389-1364.

182 White A, Resch K, Ernst E. A metanalysis of acupuncture techniques for smoking cessation. Tob Control 1999; 8: 393-397.

183 Yiming C, Changxin Z, Ung WS, Lei Z, Kean LS. Laser acupuncture for adolescent smokers - a randomised, double-blind controlled trial. Am J Chin Med 2000; 28: 443-449.

184 Abbot NC, Stead LF, White AR, Barnes J, Ernst E. Hypnotherapy for smoking cessation. Cochrane Database Syst Rev 1998; 2: CD001008.

185 Bolliger CT, Zellweger JP, Danielsson T, et al. Smoking reduction with oral nicotine inhalers: double blind, randomised clinical trial of efficacy and safety. BMJ 2000; 321: 329-333.

186 Wennike P, Danielsson T, Landfeldt T, Westin A, Tønnesen P. Smoking reduction promotes smoking cessation: Results from a double blind, randomised, placebo-controlled trial of nicotine gum with 2-year follow-up. Addiction 2003; 98: 1395-1402.

187 Hughes JR, Cummings KM, Hyland A. Ability of smokers to reduce their smoking and its association with future smoking cessation. Addiction 1999; 94: 109-114.

188 Gotfredsen N, Prescott E, Osler M, Vestbo J. Predictors of smoking reduction and cessation in a cohort of Danish moderate and heavy smokers. Prev Med 2001; 33: 46-52.

189 Tønnesen P, Danielsson T. Cutting down smoking then stopping with nicotine replacement therapy: an innovative approach to smoking cessation. Thorax 2005; 60: Suppl. II, ii36.

190 Hughes JR, Carpenter MJ. Can medications or behavioral treatment reduce smoking in smokers not trying to quit? A review. Proceedings of the Society for Research on Nicotine and Tobacco 2005: 8.

191 Hughes JR. Smoking reduction: efficacy and implementation. Addiction 2000; 95: Suppl. 1, S3-S37.

192 Bates C, McNeill A, Jarvis M, Gray N. The future of tobacco product regulation and labelling in Europe: Implications for the forthcoming European Union directive. Tob Control 1999; 8: 225-235.
193 Fagerström KO, Hughes JR, Rasmussen T, Callas PW. Randomised trial investigating effect of a novel nicotine delivery device (Eclipse) and a nicotine oral inhaler on smoking behaviour, nicotine and carbon monoxide exposure, and motivation to quit. Tob Control 2000; 9: 327-333.

194 Gray N, Henningfield JE, Benowitz NL, et al. Toward a comprehensive long term nicotine policy. Tob Control 2005; 14: 161-165.

195 Glynn TJ, Manley MW. How to help your patients to stop smoking: A National Cancer Institute Manual for Physicians. NIH Publication No. 93-3064. Bethesda, National Institutes of Health, 1993.

196 Prochaska JO, Goldstein MG. Process of smoking cessation. Implications for clinicians. Clin Chest Med 1991; 12: 727-735.

197 Jarvis MJ, Russell MA, Saloojee Y. Expired air carbon monoxide: a simple breath test of tobacco smoke intake. BMJ 1980; 281: 484-485.

198 Heffner JE. The overarching challenge. Chest 2000; 118: Suppl. 2, 1S-3S.

199 Smith WR. Evidence for the effectiveness of techniques to change physician behavior. Chest 2000; 118: Suppl. 2, 8S$17 \mathrm{~S}$.

200 Heffner JE, Alberts WM, Irwin R, Wunderink R. Translating guidelines into clinical practice. Recommendations to the American College of Chest Physicians. Chest 2000; 118: Suppl. 2, 70S-73S.

201 Nardini S, Bertoletti R, Rastelli V, Donner CF. The influence of personal tobacco smoking on the clinical practice of Italian chest physicians. Eur Respir J 1998; 12: 1450-1453.

202 European Smoke-Free Hospital Network. http:// ensh.aphp.fr. Date last accessed: November 28, 2006. Date last modified: November 23, 2006.

203 Johnson E, Dominici F, Griswold M, Zeger SL. Disease cases and their medical costs attributable to smoking: an analysis of the national medical expenditure survey. $J$ Econometrics 2003; 112: 135-151.

204 Barendregt JJ, Bonneux L, van der Maas J. The health care costs of smoking. N Engl J Med 1997; 337: 1052-1057.

205 Ruff LK, Volmer T, Nowak D, Meyer A. The economic impact of smoking in Germany. Eur Respir J 2000; 16: 385-390.

206 Parrott S, Godfrey C, Raw M, West R, McNeill A. Guidance for commissioners on the cost effectiveness of smoking cessation interventions. Thorax 1998; 53: Suppl. 5, S1-S38.

207 Godfrey C. The economic and social costs of lung cancer and the economics of smoking prevention. Monaldi Arch Chest Dis 2001; 56: 458-461.

208 World Health Organization. Economic Consequences of Smoking (ECOS) model. WHO European Partnership Project to Reduce Tobacco Dependence. CopenhagenGeneva, World Health Organization, 1999.

209 Lazzaro C. Health and Economic Consequences of Smoking (ECOS) model. WHO European Partnership Project to Reduce Tobacco Dependence. Appendix 1. Copenhagen-Geneva, World Health Organization, 1999.

210 Parrott S, Godfrey C, Raw M. Costs of employee smoking in the workplace in Scotland. Tob Control 2000; 9: 187-192. 
211 Drummond MF, O'Brien BJ, Stoddart GL, Torrance GW. Methods for the economic evaluation of health care programmes, 2nd Edn. Oxford, Oxford University Press, 1997; pp. 109-112.

212 Gold MR, Siegel JE, Russel LB, Weinstein MC. Costeffectiveness in health and medicine. New York, Oxford University Press, 1996.

213 Maynard A. Developing the health care market. Econ J 1991; 101: 1277-1286.

214 Schulmann KA, Lorna AL, Glick HA, Eisenberg J. Cost effectiveness of low-dose zidovudine therapy for asymptomatic patients with human immunodeficiency virus (HIV) infection. Ann Int Med 1991; 114: 798-802.

215 Rutten-Van Mölken MPMH, Van Doorslaer EKA, Rutten FFH. Economic appraisal of asthma and COPD care: a literature review 1980-1981. Soc Sci Med 1992; 35: 161-175.

216 Cromwell J, Bartosch WJ, Fiore MC, Hasselblad V, Baker T. Cost-effectiveness of the clinical practice recommendations in the AHCPR guideline for smoking cessation. Agency for Health Care Policy and Research. JAMA 1997; 278: 1759-1766.

217 Department of Health. Independent inquiry into inequalities in health. London, Stationery Office, 1998.

218 NHS Centre for Reviews \& Dissemination. A rapid and systematic review of the clinical and cost effectiveness of bupropion SR and nicotine replacement therapy (NRT) for smoking cessation. York, University of York, 2002.

219 Invernizzi G, Nardini S, Bettoncelli G, et al. L'intervento del medico di medicina generale nel controllo del fumo.
Rassegna di Patologia dell'Apparato Respiratorio 2002; 17 : 55-70.

220 Baker D, Illsley R. Inequalities in health. Studies in inequality in health need careful interpretation. BMJ 1998; 317: 1659.

221 Whitfield L. Social policies "must focus on inequalities". Health Service Journal 1998; 108: 8.

222 Harris JE, Chan SW. The continuum-of-addiction: cigarette smoking in relation to price among Americans aged 15-29. Health Econ 1999; 8: 81-86.

223 Becker GS, Murphy KM. A theory of rational addiction. Journal of Political Economy 1988; 96: 675-700.

224 Becker GS, Grossman M, Murphy KM. An empirical analysis of cigarette addiction. American Econ Rev 1994; 84: 396-418.

225 Chaloupka FJ, Tauras J, Grossman M. Economic models of addiction and applications to cigarette smoking and other substance abuse. Chicago, University of Illinois 1999; pp. 1-27.

226 Chaloupka FJ. Tobacco taxation. www.impacteen.org/ generalarea_PDFs/NCSLSEATTLE111601.pdf. Date last accessed: September 22, 2006.

227 Chaloupka FJ. Price, tobacco control policies and youth and young adult tobacco use. www.impacteen.org/ generalarea_PDFs/TUPTI082401.pdf. Date last accessed: September 22, 2006.

228 Cornuz J, Gilbert A, Pinget C, et al. Cost-effectiveness of pharmacotherapies for nicotine dependence in primary care settings: a multinational comparison. Tobacco Control 2006; 15: 152-159. 